\author{
UNIVERSIDADE DE SÃO PAULO \\ FACULDADE DE MEDICINA DE RIBEIRÃO PRETO \\ DEPARTAMENTO DE GINECOLOGIA E OBSTETRÍCIA
}

RODRIGO SOLER COLTRO

Avaliação dos fatores epidemiológicos, diagnósticos e terapêuticos associados à gemelaridade e o impacto dos mesmos sobre os resultados neonatais

Ribeirão Preto

2017 
Avaliação dos fatores epidemiológicos, diagnósticos e terapêuticos associados à gemelaridade e o impacto dos mesmos sobre os resultados neonatais

\title{
Versão Original
}

Dissertação apresentada à Faculdade de Medicina de Ribeirão Preto da Universidade de São Paulo para obtenção do título de Mestre em Medicina

\author{
Área de Concentração:Tocoginecologia \\ Orientadora: Profa. Dra. Alessandra Cristina Marcolin
}

Ribeirão Preto

2017 
Autorizo a reprodução e divulgação total ou parcial deste trabalho, por qualquer meio convencional ou eletrônico, para fins de estudo e pesquisa, desde que citada a fonte.

FICHA CATALOGRÁFICA

Coltro, Rodrigo Soler

Avaliação dos fatores epidemiológicos, diagnósticos e terapêuticos associados à gemelaridade e o impacto dos mesmos sobre os resultados neonatais / Rodrigo Soler Coltro; orientadora: Alessandra Cristina Marcolin. - Ribeirão Preto, 2017.

91 f. : il. ; $30 \mathrm{~cm}$

Dissertação (Mestrado em Medicina) - Programa de Pós-Graduação em Tocoginecologia, Departamento de Ginecologia e Obstetrícia, Faculdade de Medicina de Ribeirão Preto, Universidade de São Paulo, Ribeirão Preto, 2017.

1. Gestação gemelar. 2. Gêmeos dicoriônicos. 3. Gêmeos monocoriônicos 4. Resultados maternos. 5. Resultados perinatais. 6. Medicina fetal 
Nome: Rodrigo Soler Coltro

Título: Avaliação dos fatores epidemiológicos, diagnósticos e terapêuticos associados à gemelaridade e o impacto dos mesmos sobre os resultados neonatais

Dissertação apresentada à Faculdade de Medicina de Ribeirão Preto da Universidade de São Paulo para obtenção do título de Mestre em Medicina.

Programa de pós-graduação em Ginecologia e Obstetrícia. Área de concentração: Tocoginecologia

Aprovado em:

\section{Banca Examinadora}

Prof(a). Dr(a).:

Instituição:

Julgamento:

Assinatura:

Prof(a). Dr(a).:

Instituição:

Julgamento:

Assinatura:

Prof(a). Dr(a).:

Instituição:

Julgamento:

Assinatura: 


\section{DEDICATÓRIA}

Dedico este trabalho integralmente à minha esposa Nathália, a meus pais Alcides

e Maria Dolores e a meu irmão Pedro, que sempre me apoiaram e me

incentivaram nas minhas escolhas e decisões. 


\section{AGRADECIMENTOS}

À minha orientadora, Professora Doutora Alessandra Cristina Marcolin, pelo estímulo incessante às atividades profissionais e pela compreensão e paciência em me ensinar e repassar os melhores conhecimentos científicos, além de entender a mudança de rumo na minha vida neste último ano que, por vezes, me fez atrasar algumas tarefas inerentes a esta dissertação.

À minha esposa Nathália, companheira fiel e incansável em todos os momentos, pela compreensão nas minhas ausências e apoio incondicional às minhas decisões.

A meus pais Alcides e Maria Dolores pelos ensinamentos ao longo de toda minha vida e pelo incentivo à importância dos estudos desde pequeno.

Ao meu irmão Pedro pelo companheirismo e apoio constantes e pela contribuição e sabedoria brilhante em relação às atividades acadêmicas.

A toda minha familia: tios, avós, cunhados e primos que sempre me motivaram na minha trajetória.

Aos meus amigos e colegas de trabalho de Ribeirão Preto que por diversas vezes me ajudaram na coleta de dados e no aprimoramento desta dissertação, já que em algumas ocasiões sabidamente atrapalhava o andamento de seus plantões, em especial às amigas Carolina Serri Lépore e Ana Carolina dos Santos Calderon. 
Aos colegas médicos residentes, assistentes e docentes do Departamento de Ginecologia e Obstetrícia do HCFMRP USP, local onde concluí minha residência e complementação especializada na área de Medicina Fetal.

Aos funcionários do SAME (Serviço de Arquivo Médico), pelos auxílios durante a pesquisa.

À Suleimy, que aprimorou este trabalho com seus conhecimentos de estatística.

Às gestantes que participaram deste trabalho por meio da identificação de seus prontuários e a consequente concretização do estudo 


\section{RESUMO}

COLTRO, R. S. Avaliação dos fatores epidemiológicos, diagnósticos e terapêuticos associados à gemelaridade e o impacto dos mesmos sobre os resultados neonatais. 2017. 91 f. Tese (Mestrado) - Faculdade de Medicina de Ribeirão Preto, Universidade de São Paulo, Ribeirão Preto, 2017.

Introdução: as gestações gemelares estão associadas a elevadas taxas de morbimortalidade tanto maternas quanto perinatais. Algumas intervenções tem 0 potencial de reduzir essas cifras, tais como a administração de corticosteroides prénatal, a idade gestacional (IG) de resolução e a via de parto. Porém, a magnitude com que isso ocorre ainda se mantém incerta.

Objetivos: comparar os resultados neonatais das gestações gemelares (GG) com os de gestações únicas (GU), levando-se em consideração características demográficas maternas, aquelas relacionadas à gestação atual, bem como sua idade e forma de resolução.

Métodos: trata-se de um estudo caso-controle retrospectivo que incluiu 864 gestantes e seus 1298 filhos (430 únicos e 868 gemelares). As pacientes foram pareadas segundo IG de resolução da gestação, de modo que para cada gestação gemelar foi selecionada uma paciente com gestação única, de mesma IG, no mesmo período. O desfecho primário considerado foi resultado adverso perinatal. Características demográficas maternas, antecedentes obstétricos, intercorrências gestacionais, administração de corticosteroides, via de parto e corionicidade foram avaliados como fatores de risco para índices de Apgar no $1^{\circ}$ e $5^{\circ}$ minutos, morbidade neonatal composta, óbito fetal, óbito neonatal, hipoglicemia e icterícia neonatal.

Resultados: tanto nas gestações únicas como nas gemelares, prematuridade foi fator de risco para todos os resultados adversos neonatais, especialmente em $I G<$ 32 semanas. Sofrimento fetal agudo (SFA) aumentou o risco de Apgar de $1^{\circ}$ e $5^{\circ}$ minuto $<7$ nas GU. A corticoindução reduziu o risco de índices de Apgar $<7$, tanto no $1^{\circ}$ como no $5^{\circ}$ minuto nas GG e apenas no $1^{\circ}$ minuto nas GU. Por outro lado, parto vaginal $(\mathrm{PV})$ reduziu o risco de Apgar $<7$ no $1^{\circ}$ minuto nas $\mathrm{GU}$, mas aumentou o risco para os dois resultados adversos na GG. Esse efeito relacionado ao PV não ocorreu sobre a morbidade composta, mas SFA e a monocorionicidade entre os gemelares aumentou o risco desse resultado. SFA também aumentou o risco de óbito neonatal no grupo de GG. Em ambas as populações de RN, o PV foi protetor contra hipoglicemia neonatal. A monocorionicidade, corticoindução e a prematuridade aumentaram o risco de icterícia nos RN de GG. A ausência de doenças maternas protegeu os $\mathrm{RN}$ dos resultados adversos considerados.

Conclusões: estratégias que visam reduzir prematuridade, doenças maternas e situações de hipoxemia fetal aguda contribuirão para melhores resultados obstétricos, assim como o uso do corticóide pré-natal, tanto nas GU quanto nas GG. A via de parto adequada na gemelaridade permanece controversa.

Palavras-chave: Gestação gemelar, monocorionicidade, sofrimento fetal agudo, resultado adverso neonatal, parto vaginal, corticosteroide pré-natal. 


\section{ABSTRACT}

COLTRO, R. S. Evaluation of the epidemiological, diagnostic and therapeutic factors associated with the twins and their impact on the neonatal outcomes. 2017. 91 pgs. The Thesis (Master's Degree) - Faculdade de Medicina de Ribeirão Preto, Universidade de São Paulo, Ribeirão Preto, 2017.

Introduction: The twin pregnancies are associated with high rates of morbidity and mortality in both mothers and perinatal deaths. Some interventions have the potential to reduce these figures, such as the administration of corticosteroids prenatal care, gestational age (GA) of resolution and the delivery route. However, the magnitude with which this occurs still remains uncertain.

Objectives: To compare the neonatal results of the pregnancies of twins (TP) with those of singleton gestations (SG), taking into account maternal demographic characteristics, those related to the current pregnancy, as well as their age and form of deliverv.

Methods: This was a retrospective case-control study that included 864 pregnant women and their 1298 children (430 single and 868 twins). The patients were paired according to GA for a resolution of the pregnancy, so that for each twin pregnancy, a patient was selected with single pregnancy, of the same GA, during the same period. The primary outcome was considered perinatal adverse result. Demographic characteristics of the mother, obstetric history, complications of pregnancy, administration of corticosteroids, delivery route and chorionicity were evaluated as risk factors for Apgar scores at 1 and 5 minutes, neonatal morbidity composed, fetal death, neonatal death, hypoalycemia and neonatal iaundice.

Results: In both pregnancies, prematurity was a risk factor for all adverse results, especially in GA<32 weeks. Acute fetal distress (AFD) increased the risk of an Apgar score of 1 and 5 minute $<7$ in SG. The corticoindution reduced the risk of higher Apgar scores $<7$, both on the 1st and 5th minute in TP and only in the 1st minute in SG. On the other hand, vaginal delivery (VD) reduced the risk of an Apgar score $<7$ in the 1st minute in SG, but increased the risk for the two adverse results in TP. This effect is related to the VD did not occur on morbidity composed, but AFD and monochorionicity between the twins increased the risk of that result. AFD also increased the risk of neonatal death in the group of TP. In both populations of newborn (NB), the VD was protective against neonatal hypoglycemia. The monochorionicity, corticoindution and prematurity increased the risk of jaundice in NB of TP. The absence of maternal diseases protected the NB of adverse results considered.

Conclusions: Strategies that aim to reduce prematurity, maternal diseases and situations of acute fetal hypoxemia will contribute to better outcomes, as well as the use of corticosteroids antenatal care, both in SG and in TP. The delivery route in multiple births remains controversial.

Keywords: Twin Pregnancy, monochorionicity, acute fetal distress, adverse neonatal outcome, vaginal delivery, corticosteroid prenatal. 


\section{LISTA DE FIGURAS}

Figura 1. Causas de exclusão de pacientes do grupo de gestações gemelares....... 41

Figura 2. Causas de exclusão de pacientes do grupo de gestações únicas............. 41 


\section{LISTA DE TABELAS}

Tabela 1. Características demográficas maternas, gestacionais e neonatais da população estudada 48

Tabela 2. Influência das características demográficas maternas e relacionadas à gestação sobre o Apgar de primeiro minuto dos recém-nascidos de gestações únicas e gemelares

50

Tabela 3. Efeito das características demográficas maternas e relacionadas à gestação sobre o Apgar de primeiro minuto dos recém-nascidos de gestações únicas e gemelares (análise multivariada)

Tabela 4. Influência das características demográficas maternas e relacionadas à gestação sobre o Apgar de quinto minuto dos recém-nascidos de gestações únicas e gemelares

Tabela 5. Efeito das características demográficas maternas e relacionadas à gestação sobre o Apgar de quinto minuto dos recém-nascidos de gestações únicas e gemelares (análise multivariada)

Tabela 6. Influência das características demográficas maternas e relacionadas à gestação sobre morbidade composta dos recém-nascidos de gestações únicas e gemelares

Tabela 7. Efeito das características demográficas maternas e relacionadas à gestação sobre morbidade composta dos recém-nascidos de gestações únicas e gemelares (análise multivariada)

55

Tabela 8. Influência das características demográficas maternas e relacionadas à gestação sobre óbito neonatal dos recém-nascidos de gestações únicas e gemelares 56

Tabela 9. Efeito das características demográficas maternas e relacionadas à gestação sobre óbito neonatal dos recém-nascidos de gestações únicas e gemelares (análise multivariada)

57

Tabela 10. Influência das características demográficas maternas e relacionadas à gestação sobre a ocorrência de hipoglicemia dos recém-nascidos de gestações únicas e gemelares 
Tabela 11. Efeito das características demográficas maternas e relacionadas à gestação sobre hipoglicemia neonatal dos recém-nascidos de gestações únicas e gemelares (análise multivariada)

Tabela 12. Influência das características demográficas maternas e relacionadas à gestação sobre a ocorrência de icterícia dos recém-nascidos de gestações únicas e gemelares

Tabela 13. Efeito das características demográficas maternas e relacionadas à gestação sobre icterícia neonatal dos recém-nascidos de gestações únicas e gemelares (análise multivariada)

Tabela 14. Influência das características demográficas maternas e relacionadas à gestação sobre a ocorrência de óbito fetal em gestações únicas e gemelares. 


\section{LISTA DE ABREVIATURA E SIGLAS}

$A C O G$

DA

DC

DP

DZ

ECN

EHI

ESHRE

EUA

FMRP-USP

HAC

HCFMRP-USP
American College of Obstetricians and Gynecologists

Diamnióticas

Dicoriônicas

Desvio padrão

Dizigóticas

Enterocolite necrosante

Encefalopatia hipóxico-isquêmica

European Society of Human Reproduction and Embryology

Estados Unidos da América

Faculdade de Medicina de Ribeirão Preto - Universidade de São

Paulo

Hipertensão arterial crônica

Hospital das Clínicas da Faculdade de Medicina de Ribeirão

Preto - Universidade de São Paulo

HIC

Hemorragia intracraniana

IC

Intervalo de confiança

Idade Gestacional

IMC

Índice de massa corpórea

LMPV

Leucomalácia periventricular

MA

Monoamnióticas

MC

Monocoriônicas

MPN

Mortalidade perinatal

$M Z$

Monozigóticas 


$\begin{array}{ll}\text { NICE } & \text { National Institute for Health and Clinical Excellence } \\ \text { NV } & \text { Nascidos vivos } \\ \text { OR } & \text { Odds Ratio } \\ \text { PC } & \text { Paralisia cerebral } \\ \text { PPT } & \text { Parto pré-termo } \\ \text { PT } & \text { Pré-termo } \\ \text { RCIU } & \text { Restrição de crescimento intrauterino } \\ \text { RN } & \text { Recém-nascidos } \\ \text { RR } & \text { Risco relativo } \\ \text { SAS } & \text { Statistical Analysis System } \\ \text { SDR } & \text { Síndrome do desconforto respiratório } \\ \text { SMFM } & \text { Society for Maternal-Fetal Medicine } \\ \text { SFA } & \text { Sofrimento fetal agudo } \\ \text { SFC } & \text { Sofrimento fetal crônico } \\ \text { STFF } & \text { Síndrome de transfusão feto-fetal } \\ \text { TPPT } & \text { Trabalho de parto pré-termo } \\ \text { UTI } & \text { Unidade de terapia intensiva }\end{array}$




\section{LISTA DE SÍMBOLOS}

a

0

$\%$

$=$

$>$

$\geq$

$\leq$

< Comparação - menor que

Kg Quilogramas

mg Miligramas

$\mathrm{cm} \quad$ Centímetros

m Metros

$\mathrm{m}^{2} \quad$ metro ao quadrado

X Versus

I número romano - um

॥ número romano - dois

III número romano - três

N número romano - quatro

V número romano - cinco 


\section{ÍNDICE}

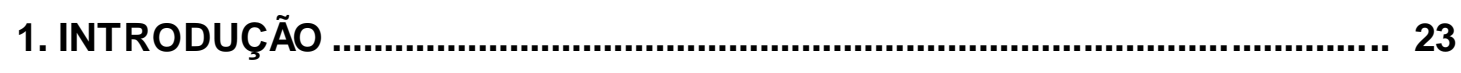

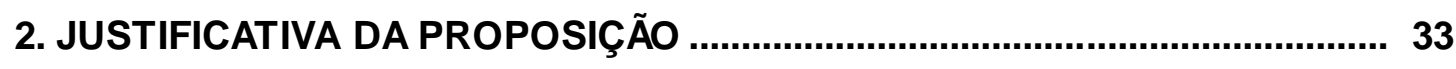

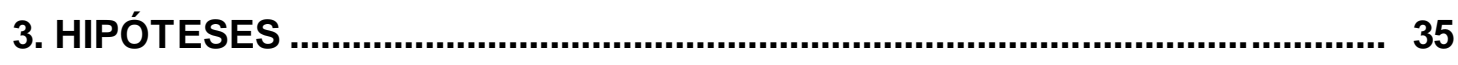

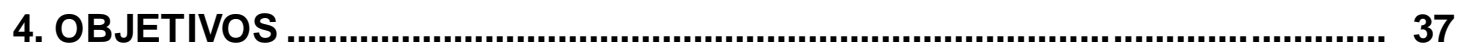

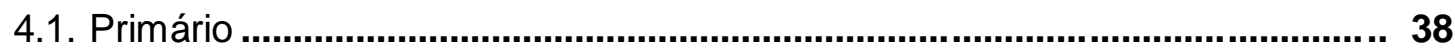

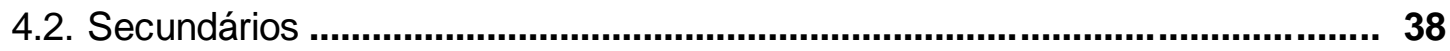

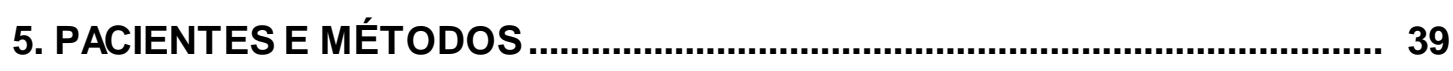

5.1. Desenho do estudo ................................................................................. 40

5.2. Desfechos e definições ................................................................................. 42

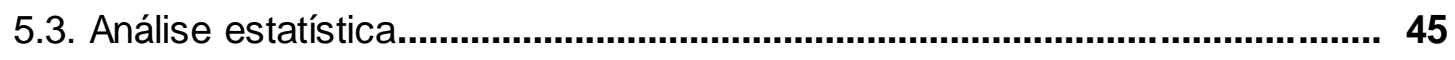

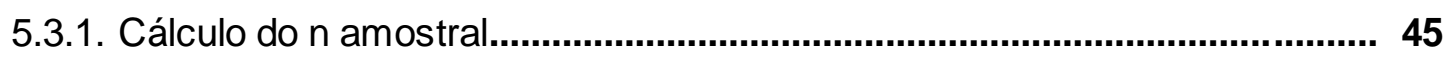

5.3.2 Análises e modelos estatísticos .................................................................. 45

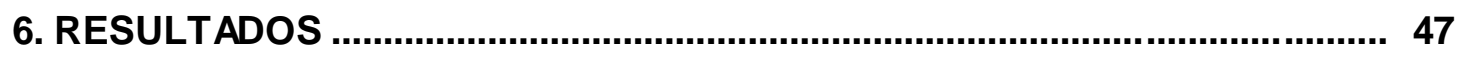

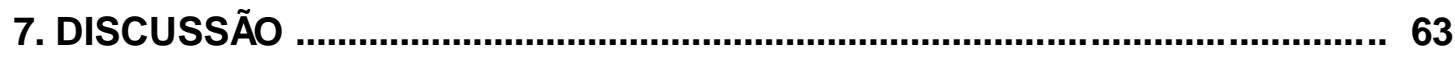

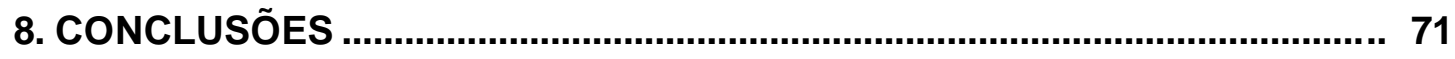

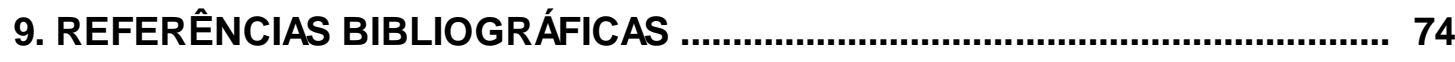

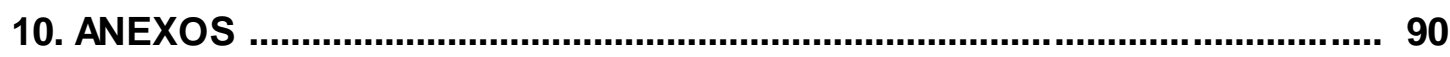




\section{INTRODUÇÃO}


A gestação múltipla ou gemelar consiste na presença simultânea de dois ou mais conceptos na cavidade uterina e resulta da fecundação de um ou mais oócitos. O estudo da gemelaridade é especialmente motivado pela correlação positiva entre este tipo de gestação e altas taxas de morbimortalidade maternas e perinatais (Corsello; Piro, 2010). Nessas gestações, a morbimortalidade perinatal é 3 a 7 vezes maior que a observada em gestações únicas (Hack et al., 2008). A incidência da gestação múltipla varia entre os diversos países avaliados, sendo de 6.7:1000 nascidos vivos (NV) no Japão, 10:1000 na Europa, 32:1000 nos Estados Unidos (EUA) e de 40:1000 em alguns países africanos (Dodd et al., 2010; Chauhan et al., 2010; Martin et al., 2012). As taxas de gemelaridade sofreram importante incremento nas últimas três décadas devido às gestações em idade materna avançada e uso das técnicas de reprodução assistida, incluindo tanto o uso de drogas indutoras da ovulação bem como da fertilização in vitro com transferência de embriões (Eriksson; Fellman, 2007).

As gestações múltiplas podem ser classificadas segundo a zigoticidade (número inicial de zigotos) e a corionicidade (número de placentas) (Bhide; Thilaganathan, 2004; Corsello; Piro, 2010). Dois terços das gestações gemelares espontâneas são dizigóticas (DZ) e portanto, resultam da fecundação de mais de um óvulo, com produtos conceptuais apresentando materiais genéticos distintos. Nesse caso, cada zigoto desenvolve seus próprios córion e âmnio tornando-as, portanto, dicoriônicas (DC) e, obviamente, diamnióticas (DA). Já as monozigóticas (MZ) resultam da divisão da massa embrionária inicial comum e os produtos conceptuais apresentam carga genética idêntica (Bhide; Thilaganathan, 2004; Rao et al., 2004; Corsello; Piro, 2010). Essas gestações têm apresentação variável a depender do momento em que ocorre a divisão da massa embrionária (Simpson, 2015). Em um terço dos gêmeos $M Z$, a divisão ocorre em até $72 \mathrm{~h}$ após a fecundação, resultando em gestações DC/DA, de maneira semelhante ao que ocorre com as gestações DZ. Por outro lado, em dois terços dos casos, a divisão acontece entre $\circ 3^{\circ}$ e $09^{\circ}$ dia após a fecundação, ocasião em que já ocorreu a diferenciação das células que originarão o córion, havendo a formação de apenas uma placenta, mas duas cavidades amnióticas, ou seja, uma gestação 
monocoriônica (MC) e DA. Em 1\% das gestações $M Z$, a massa embrionária se dividirá após o 9ำ dia da fertilização e os gêmeos compartilharão a placenta e a cavidade amniótica, dando origem a uma gestação MC e monoamniótica (MA). Quando o processo de divisão é tardio, após o $12^{\circ}$ dia, ocorre falha na separação completa dos embriões, o que dá origem aos gêmeos unidos.

A gestação múltipla está associada a taxas significativamente maiores de doenças gestacionais maternas quando comparada à gestação com feto único. Hiperêmese, anemia, aborto, síndromes hipertensivas gestacionais e suas complicações, diabetes gestacional, sangramentos de segunda metade da gestação, provocados por descolamento de placenta normalmente inserida e prévia e tromboembolismo venoso são mais frequentes nas gestações múltiplas (Schwartz et al., 1999; Conde-Agudelo et al., 2000; Ananth et al., 2001; Ananth et al., 2003; Campbell; Templeton, 2004; Salihu et al., 2005; Catov et al., 2007; ACOG, 2014; Santana et al., 2016). Segundo Day e colaboradores (2005), a ocorrência de desordens hipertensivas é proporcional ao número total de fetos, com incidências de $6.5 \%, 12.7 \%$ e $20.0 \%$, em gestações com um, dois e três fetos, respectivamente. Quando a hipertensão ocorre, geralmente se dá em idades gestacionais mais precoces e com formas clínicas atípicas (Sibai et al., 2000). Cabe destacar que as prevalências das complicações maternas parecem ser maiores em mulheres com idades mais avançadas e nas gestações consequentes a técnicas de reprodução assistida (Lynch et al., 2002; ACOG, 2014).

Quanto à resolução da gestação, observam-se taxas de cesárea mais elevadas nas gestações múltiplas (Conde-Agudelo et al., 2000; Campbell; Templeton, 2004; ACOG, 2014; Santana et al., 2016). Os trabalhos mostram cifras de cesáreas eletivas duas vezes maiores quando essas gestações são comparadas com as de fetos únicos. Além das indicações de cesárea semelhantes às das gestações únicas, na gemelaridade outras indicações específicas são responsáveis por aumentarem a ocorrência desse procedimento, tais como apresentação pélvica do primeiro feto (que é mais frequente nos gemelares), monoamnionicidade, gêmeos conjugados e aquelas relacionadas às complicações intraparto do segundo gemelar (que também são mais frequentes) (Barrett, 2014). 
Quando comparadas às gestações únicas, gestações gemelares apresentam complicações puerperais mais frequentemente. Vários estudos concordam que há risco aumentado de hemorragia pós-parto, tanto primária como secundária, e de outras intercorrências, tais como maior necessidade de remoção manual da placenta (Campbell; Templeton, 2004; ACOG, 2014; Santana et al., 2016). Nessas gravidezes, as mulheres têm risco duas vezes maior de apresentarem condições potencialmente ameaçadoras de vida, três vezes mais "near miss" e risco quatro vezes maior de morrerem (Santana et al., 2016). Hemorragia puerperal e disfunções de órgãos estão fortemente associadas a resultados maternos graves, assim como a necessidade de transfusão sanguínea e admissão materna à unidade de terapia intensiva (Vogel et al., 2013; Santana et al., 2016).

Considerando os resultados perinatais, várias complicações são significativamente maiores na gestação múltipla quando comparada à gestação com feto único. O parto pré-termo (PPT) ocorre em até $50 \%$ dos casos e, devido a essa elevada frequência, a prematuridade é o principal fator determinante das altas taxas de morbimortalidade neonatal e infantil, da permanência prolongada dos recém-nascidos (RN) em unidades de terapia intensiva (UTI) neonatal e do alto custo no manejo dessa condição (Doss et al., 2012). O custo médio do parto em gestações com fetos únicos é de US\$ 9.845 e no caso de gemelares é de US\$ 37.947 (Kinzler et al., 2000). Mulheres com gestações gemelares têm risco seis vezes maior de terem um PPT e probabilidade 13 vezes maior desse parto ocorrer antes da $32^{\mathrm{a}}$ semana de gestação, quando comparadas às gestações únicas (Martin et al., 2011). A idade gestacional (IG) média de resolução da gestação é inversamente proporcional ao número de fetos, de tal modo que a duração média da gestação com dois, três ou quatro fetos é de 35, 32-34 e 28-30 semanas, respectivamente (Ramsey; Repke, 2003). O risco de PPT ainda é maior nas gestações MC quando comparadas às DC (Sebire et al., 1997; Hack et al., 2006; Goya et al., 2015).

Alguns trabalhos existentes na literatura mostram que os resultados neonatais e pesos de nascimento dos $\mathrm{RN}$ de gestações múltiplas são semelhantes aos de RN de gestações únicas com mesma IG. Apesar de os RN gemelares terem 
maior risco de morbidade respiratória aguda, como a síndrome do desconforto respiratório (SDR), eles não apresentam maior incidência de doença pulmonar crônica (Shinwell, 2005). Diferenças significativas na prevalência de outras morbidades apresentadas por RN PT, tais como hemorragia intraventricular, LMPV, retinopatia da prematuridade, ECN, ducto arterioso patente e infecção nosocomial também não são observadas entre gemelares e RN de gestações únicas (Garite et al., 2004; Lee et al., 2006). Ao considerarmos os gemelares PT tardios, alguns estudos demonstram maiores taxas de complicações quando comparados aos RN no termo da gestação. Em seu estudo retrospectivo de gemelares nascidos entre os anos de 1991 e 2009, no estado do Alabama (EUA), Doss e colaboradores (2012) mostraram que as taxas de morbidade neonatal composta, internação na UTI neonatal, suspeita de sepse, qualquer dificuldade respiratória e hiperbilirrubinemia foram menores à medida que a IG avançou de 36 a 38 semanas de gestação. Esses autores mostraram que os riscos de admissão a UTI, morbidade neonatal composta e desordens respiratórias foram, respectivamente, 6.3, 6.0 e 4.7 vezes maiores na $36^{a}$ semana quando essa foi comparada à $38^{2}$ semana de IG ao nascimento, mesmo ao se considerar corionicidades diferentes.

A taxa geral de óbito fetal em gestações múltiplas é maior do que em gestações únicas: em 2009, foi de 12.3 por 1.000 gestações com dois fetos e 31.1 por 1.000 gestações trigemelares, em comparação à taxa de 5.0 por 1.000 gestações de fetos únicos (NICE, 2011). A mortalidade perinatal (MPN) e a morbidade dos gêmeos é 3 a 7 vezes maior que na gestação única (Hack et al., 2008) e são secundárias à prematuridade e outras complicações pré-natais. Além do aumento da MPN e da morbidade, os gemelares apresentam maior risco de desordens do crescimento e do desenvolvimento em longo prazo, incluindo paralisia cerebral (PC), comprometimento cognitivo, atraso de fala e linguagem, dificuldades de aprendizagem e distúrbios de comportamento (ESHRE, 2000). Vários são os mecanismos causais aventados para explicar as maiores prevalências de PC em $\mathrm{RN}$ de gestações múltiplas, considerando que resulta de dano cerebral ocorrido durante a gravidez ou no período neonatal imediato. Segundo Pharoah (2006), após excluir as causas pós-natais de PC (cerca de 10\% dos casos) e periparto 
relacionadas à asfixia, que não são consideradas mais frequentes em gemelares quando comparados a fetos únicos (10\% dos casos), estima-se que aproximadamente $80 \%$ dos casos de PC sejam secundários à intercorrências prénatais.

A restrição de crescimento intrauterino (RCIU), assim como a prematuridade, é uma intercorrência bastante frequente na gemelaridade, acometendo até $25 \%$ destas gestações (Russell et al., 2007). Pelo menos um dos fetos é restrito em 34\% das gestações MC e em $23 \%$ das DC e o acometimento de ambos os fetos é cerca de quatro vezes maior na primeira quando comparado à segunda (Sebire et al., 1998). Por outro lado, a discordância de crescimento fetal ocorre em 5 a 15\% dessas gestações e também está associada a maiores taxas de morbimortalidade perinatal (Nassar et al., 2003; ACOG, 2009). Na literatura, existem controvérsias sobre o limite a partir do qual se faz o diagnóstico de crescimento discordante, porém o valor mais aceito como clinicamente relevante é a diferença $\geq 25 \%$ entre os pesos dos gêmeos (D'Antonio et al. 2013). Embora IG no nascimento e peso ao nascer sejam os preditores mais importantes do desfecho pós-natal, crescimento discordante também é uma variável independente associada a desfecho adverso (Breathnach et al., 2011). Existirá comprometimento perinatal sempre que houver discordância de peso, mesmo se ambos os gêmeos tiverem peso adequado para a IG, especialmente se considerarmos a gestação gemelar MC (Harper et al., 2013). O crescimento fetal deficiente pode ser decorrente de diferenças na placentação, no potencial genético individual (no caso das gestações DZ), de anormalidades de inserção do cordão e de complicações da monocorionicidade relacionadas às anastomoses vasculares placentárias (Rao et al., 2004; Breathnach; Malone, 2012). O dado sobre o qual não se tem dúvida é que distúrbio do crescimento está associado a maior probabilidade de anomalias, PPT eletivo, óbito fetal, acidose no nascimento, maior taxa de admissão do RN a UTI, infecção, desordens respiratórias e óbito neonatal precoce (ACOG, 2009).

As intercorrências maternas e perinatais são mais frequentes nas gestações $M C$ quando comparadas às DC. Gêmeos $M C$ têm risco 3 a 10 vezes maior de morbimortalidade perinatal. Anomalias congênitas são mais frequentes em 
gestações gemelares quando comparadas às gestações únicas (Sperling et al., 2007). Embora a taxa de anomalias por feto permaneça aproximadamente a mesma em gestações DZ, a taxa global por gravidez fica em torno de $3 \%$ a $4 \%$ e, se considerarmos as gestações MC, a frequência de anomalias é $2-4$ vezes maior que nas DC (Glinianaia et al., 2008; Masheer et al., 2015). Além disso, em 90\% das gestações gemelares com anomalias congênitas, apenas um gêmeo é afetado. No caso de ambos serem afetados, em $20 \%$ dos gêmeos MC e em $10 \%$ dos gêmeos DC o defeito estrutural será o mesmo (Boyle et al., 2013). Malformações cardíacas são as anomalias mais frequentemente encontradas, especialmente em gestações MC (Sperling et al., 2007).

Existem algumas complicações das gestações MC que ocorrem secundariamente à existência de anastomoses presentes entre as circulações dos fetos que compartilham a mesma placenta. Isso resultará em desequilibrio na perfusão dos gêmeos envolvidos, com elevada taxa de crescimento fetal discordante, hipóxia e anomalias congênitas. A síndrome de transfusão feto-fetal (STFF) é uma dessas complicações específica e exclusiva da gemelaridade MC, comprometendo severamente 10 a 15\% das gestações (Galea et al., 2005). Ela ocorre devido à transferência não balanceada de sangue entre as circulações de ambos os fetos, por meio das anastomoses vasculares arteriovenosas placentárias (SMFM, 2013). Assim, o gêmeo doador apresenta anemia e RCIU grave, acompanhadas de oligúria e oligohidrâmnio, enquanto no gêmeo receptor ocorre sobrecarga circulatória e policitemia, com possibilidade de complicações cardiovasculares e hidropsia (Harkness; Crombleholme, 2005). Quintero e colaboradores (1999) tentaram estabelecer estágios da STFF (5 estágios), com base nos achados pré-natais ecográficos e história natural da doença, objetivando descrever sua gravidade e direcionar seu manejo. A sobrevida neonatal varia de $86 \%$ no estágio I (menos grave) a 0 - 30\% em estágios $\geq$ III (mais graves, com comprometimento Dopplervelocimétrico fetal), caso não seja realizada qualquer intervenção, especialmente quando a doença se manifesta antes da 26ª semana de gestação (SMFM, 2013). A fotocoagulação com laser das anastomoses placentárias, por fetoscopia, é considerada pela maioria dos especialistas como a 
melhor abordagem disponível para os estágios além do I (Quintero et al., 2016). Mesmo nos casos de STFF em que se faz a intervenção com laser, observa-se taxa de MPN de $30-50 \%$ e risco de comprometimento neurológico de $5-20 \%$ (SMFM, 2013). Por causa das anastomoses vasculares existentes na gestação $M C$, na eventualidade do óbito de um gemelar, o risco de morte e lesão neurológica do $2^{\circ}$ gemelar é de 10\% e 30\%, respectivamente (Ong et al., 2006; Mackie et al., 2016).

Os gêmeos MA representam uma rara e relevante complicação da monocorionicidade ( $1 \%$ das gestações $\mathrm{MZ}$ ). A perda fetal, que ocorre em $30-70 \%$ dos casos, se deve ao enovelamento dos cordões umbilicais inseridos em proximidade na placenta única, com consequente estiramento e interrupção do fluxo em situações de movimentação fetal e parto (Rao et al., 2004). A prematuridade e as malformações são intercorrências que estão associadas a essa condição e que colaboram para 0 aumento das taxas de morbimortalidade perinatal na gemelaridade (Rossi; Prefumo, 2013).

Apesar de todo esse conhecimento existente sobre a gemelaridade, alguns pontos permanecem controversos. Quais são as características maternas e da história obstétrica que realmente interferem com os resultados maternos e perinatais? A administração de corticóide antenatal reduz as complicações relacionadas à prematuridade como faz em gestações únicas? Considerando a IG de nascimento, as prevalências dessas complicações são semelhantes quando se compara gemelares com fetos únicos? A via de parto interfere nos resultados neonatais?

Apesar da importância da prematuridade na gemelaridade, a capacidade de predizê-la ainda é inferior à sua importância clínica, com testes como a determinação da fibronectina fetal em secreções cervicovaginais e a avaliação ecográfica do comprimento cervical apresentando valores preditivos muito aquém do ideal (Ness et al., 2007; Fox et al., 2009; Chauhan et al., 2010). As estratégias existentes que visam prevenir prematuridade, assim como nas gestações únicas, carecem de evidências de boa qualidade para respaldá-las (Berghella et al., 2005; Fox et al., 2009; Crowther; Han, 2010; Chauhan et al., 2010; Dodd et al., 2013; Yamasmit et al., 2015). Assim como em gestações únicas, uma vez diagnosticado 
o trabalho de PPT, a tocólise instituída como terapêutica não promove redução do parto dentro de 7 dias de tratamento, de óbito perinatal ou das complicações neonatais relacionadas a prematuridade (Neilson et al., 2014; Flenady et al., 2014a; Flenady et al., 2014b). Por outro lado, a administração de corticosteroides para indução da maturidade fetal, administrada entre a $24^{\mathrm{a}}$ e $34^{\mathrm{a}}$ semana de gestação, promove redução da morbimortalidade neonatal relacionada à prematuridade, porém não a diminui na mesma proporção que faz nas gestações únicas (Blickstein et al., 2005; Blickstein et al., 2006). Esses dados nos estimulam a realizar mais estudos comparativos, considerando gestantes que receberam ou não corticosteroides, para averiguar o real efeito desta intervenção.

As influências da IG e da via de parto sobre os resultados neonatais continuam sendo motivo de debate na Obstetrícia moderna. A análise da curva de

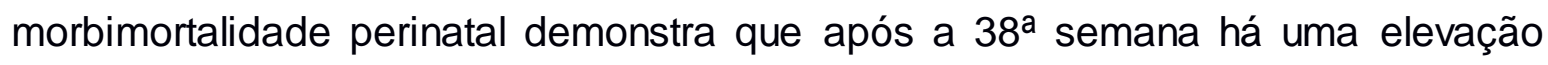
significativa dessa taxa (Cheung et al., 2000; Hartley et al., 2001; Sairam et al., 2002; Soucie et al., 2006). No entanto, por serem epidemiológicos, esses estudos são limitados pela falta de informações adequadas sobre IG, corionicidade e complicações da gravidez. Além disso, eles não possuem dados sobre os desfechos perinatais (Doss et al, 2012). Consensos de especialistas como o Royal College of Obstetricians and Gynaecologists (2013) e o American College of Obstetricians and Gynecologists (2014) e alguns trabalhos mais recentes destacam que gestações DC devam ser resolvidas na 38 ${ }^{\text {a }}$ semana e MC, por apresentam maiores taxas de morbimortalidade que as DC, devam ser resolvidas uma semana antes, portanto na 37로 semana (Dias; Akolekar, 2014). Mas, cumpre destacar que faltam mais estudos, inclusive ensaios randomizados com grandes casuísticas, que demonstrem claramente a IG ideal para resolução da gestação múltipla.

Sobre qual seria a melhor via de parto na gemelaridade, ainda há muitas controvérsias e, para adotá-la deve-se levar em consideração múltiplos fatores, tais como IG, número de fetos e suas apresentações, corionicidade e experiência de quem assiste o parto (ACOG, 2014). Alguns estudos de coorte mostraram que 0 segundo gemelar tem risco significativamente maior de desfecho adverso quando comparado ao primeiro e que esse risco é reduzido quando a resolução da gestação 
se faz por cesárea (Smith et al., 2005; Armson et al., 2006; Smith et al., 2007). Porém, de acordo com estudos mais recentes e de melhor qualidade, mulheres com gestações gemelares DA, com os primeiros gemelares em apresentação cefálica, independentemente da apresentação do segundo gemelar, são candidatas ao parto vaginal, uma vez que cesárea eletiva não reduz MPN ou morbidade neonatal grave em comparação ao parto vaginal (Barrett et al., 2013; Vogel et al., 2014; Easter et al., 2016), desde que quem assiste o parto seja experiente em parto pélvico (D'Alton, 2010). Resultados adversos perinatais são mais frequentes para o segundo gemelar, porém a cesárea não reduz esse risco (Lie et al., 2000; Barrett et al., 2013; Vogel et al., 2014). Faltam trabalhos mais contundentes que avaliem esse desfecho. Por outro lado, a via de parto ideal para mulheres com gestações múltiplas com mais de dois fetos permanece desconhecida. Apesar desses achados, o manejo obstétrico da gestação gemelar ainda é um assunto controverso. Como podemos ver pelo exposto acima, trabalhos que avaliem aspectos da gestação gemelar são bem-vindos à literatura, pois têm o potencial de esclarecer alguns pontos ainda bastante controversos dessa condição obstétrica. Esse dado nos estimula a desenvolver a presente pesquisa. 
2. JUSTIFICATIVA DA PROPOSIÇÃO 
As gestações gemelares estão associadas a elevadas taxas de morbimortalidade tanto maternas quanto perinatais. As intercorrências maternas ocorrem principalmente por causa das modificações fisiológicas mais intensas que ocorrem nessa condição quando comparada a gestação com feto único. As complicações perinatais estão relacionadas principalmente à prematuridade, RCIU, doenças da monocorionicidade e distocias no parto. Na gestação única, a morbimortalidade secundária à prematuridade pode ser reduzida com a administração materna de corticóide. Porém, na gemelaridade o efeito da corticoindução sobre a maturidade fetal parece não ocorrer na mesma magnitude com que o faz nas gestações únicas e são poucos os trabalhos que avaliaram esse aspecto. Além disso, ainda existem muitas controvérsias ao se considerar a IG ideal de resolução da gestação, bem como a via de parto adequada. Sendo assim, é plenamente justificável um trabalho que analise mais profundamente as intercorrências perinatais, especialmente ao se levar em consideração o uso de corticóide anteparto, que avalie essas complicações à luz da IG de resolução da gestação e da via de parto escolhida para esse fim. Dessa forma, um número maior de informações estará disponível para que condutas mais apropriadas sejam adotadas na assistência à gestação múltipla. 
3. HIPÓTESES 
3.1. Hipótese H0: não há diferenças nos desfechos clínicos neonatais de gestações gemelares quando os RN são comparados aos de gestações únicas;

3.2. Hipótese H1: há diferenças nos desfechos clínicos neonatais de gestações gemelares quando os RN são comparados aos de gestações únicas. 
4. OBJETIVOS 


\subsection{Primário:}

4.1.1. Analisar os resultados neonatais das gestações múltiplas resolvidas em um serviço terciário, levando-se em consideração a corionicidade, o uso de corticóide pré-natal, a IG e a via de parto.

\subsection{Secundários:}

4.2.1. Analisar a influência das variáveis demográficas maternas, aquelas relacionadas à gestação atual e das intercorrências obstétricas sobre o desfecho índice de Apgar < 7 no 1ํ minuto de vida;

4.2.2. Analisar a influência das variáveis demográficas maternas, aquelas relacionadas à gestação atual e das intercorrências obstétricas sobre o desfecho índice de Apgar < 7 no 5ํ minuto de vida;

4.2.3. Analisar a influência das variáveis demográficas maternas, aquelas relacionadas à gestação atual e das intercorrências obstétricas sobre o desfecho morbidade neonatal composta;

4.2.4. Analisar a influência das variáveis demográficas maternas, aquelas relacionadas à gestação atual e das intercorrências obstétricas sobre o desfecho óbito neonatal;

4.2.5. Analisar a influência das variáveis demográficas maternas, aquelas relacionadas à gestação atual e das intercorrências obstétricas sobre o desfecho hipoglicemia neonatal;

4.2.6. Analisar a influência das variáveis demográficas maternas, aquelas relacionadas à gestação atual e das intercorrências obstétricas para o desfecho icterícia neonatal;

4.2.7. Analisar a influência das variáveis demográficas maternas, aquelas relacionadas à gestação atual e das intercorrências obstétricas sobre o desfecho óbito fetal. 
5. PACIENTES E MÉTODOS 


\section{Desenho do estudo}

Trata-se de um estudo caso-controle retrospectivo em que foram comparados desfechos clínicos perinatais de gestações únicas e gestações gemelares expostas a diferentes fatores de risco no período estudado. Foram avaliadas pacientes assistidas pelo Setor de Gestação de Alto Risco do Departamento de Ginecologia e Obstetrícia do Hospital das Clínicas de Ribeirão Preto da Faculdade de Medicina de Ribeirão Preto da Universidade de São Paulo (HCFMRP-USP). As pacientes foram pareadas segundo a IG de resolução da gestação, de modo que para cada gestação gemelar foi selecionada uma paciente com gestação única, de mesma IG, cujo parto se deu imediatamente antes ou depois daquela (dentro de \pm uma semana). Caso a paciente com gestação única fosse excluída por algum critério, uma nova paciente, com resolução da gestação na data o mais próxima possível desta, seria selecionada. O HCFMRP-USP possui uma maternidade coordenada pelo Departamento de Ginecologia e Obstetrícia da Faculdade de Medicina de Ribeirão Preto-USP, com capacidade para 34 leitos, que atende cerca de 2400 gestantes de alto risco anualmente. O período considerado para coleta de dados foi de janeiro de 2005 a dezembro de 2014. Esse amplo período de análise levou em consideração um marco na assistência à gestação múltipla: o uso do corticóide anteparto de rotina em no máximo dois ciclos, a partir de 2010. Os registros das pacientes foram obtidos através de levantamento de prontuários médicos para fins de pesquisa, realizado pelo serviço de processamento de dados do hospital. Os dados desses prontuários foram coletados, após a aprovação do projeto de pesquisa pela Comissão de Pesquisa do Departamento de Ginecologia e Obstetrícia e pelo Comitê de Ética em Pesquisa do HCFMRP-USP, oo processo HCRP: $6431 / 2014$ (ANEXO 1). Todo o estudo seguiu os preceitos estabelecidos pela iniciativa STROBE e está de acordo com a Resolução 466/12 do Conselho Nacional de Saúde. Após as exclusões realizadas ao longo do estudo, foram utilizados para análise os dados de 430 gestações com fetos únicos e 434 gestações gemelares (com dois fetos) (Figura 1 e 2). 
488 pacientes foram inicialmente identificadas

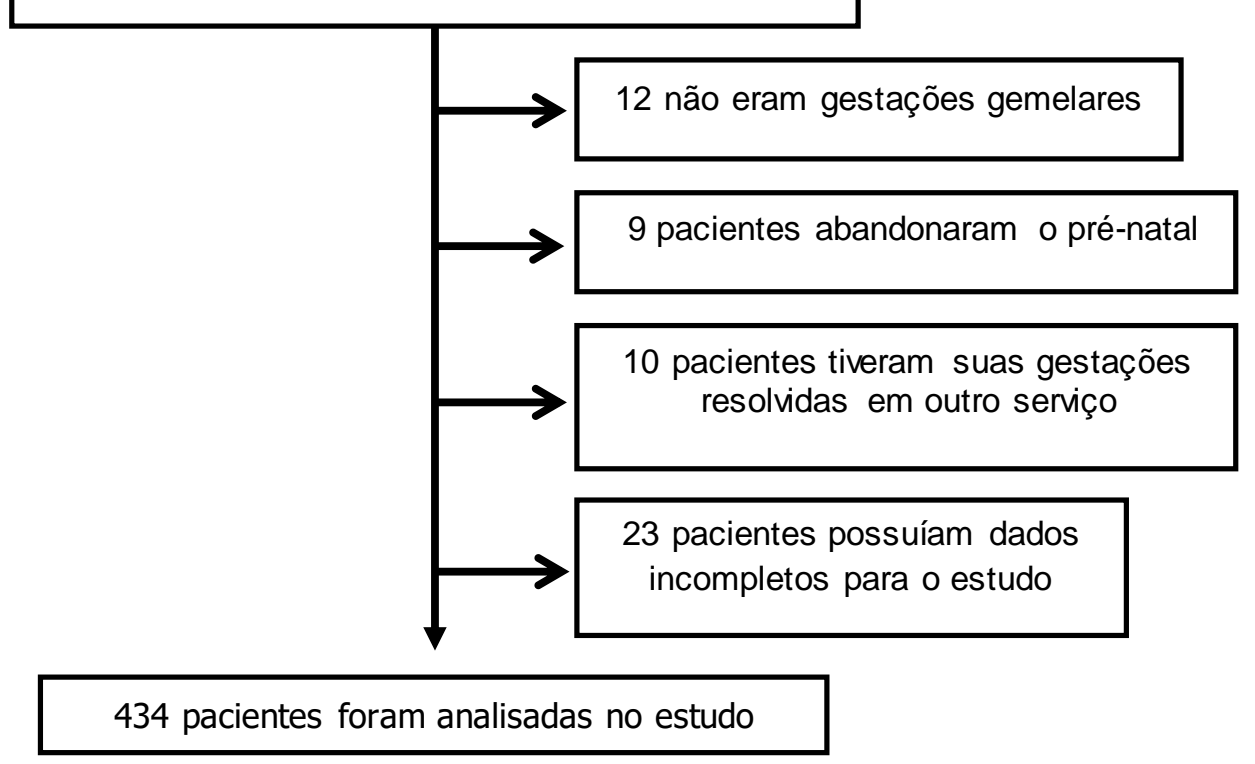

Figura 1. Causas de exclusão de pacientes do grupo de gestações gemelares

512 pacientes foram inicialmente identificadas

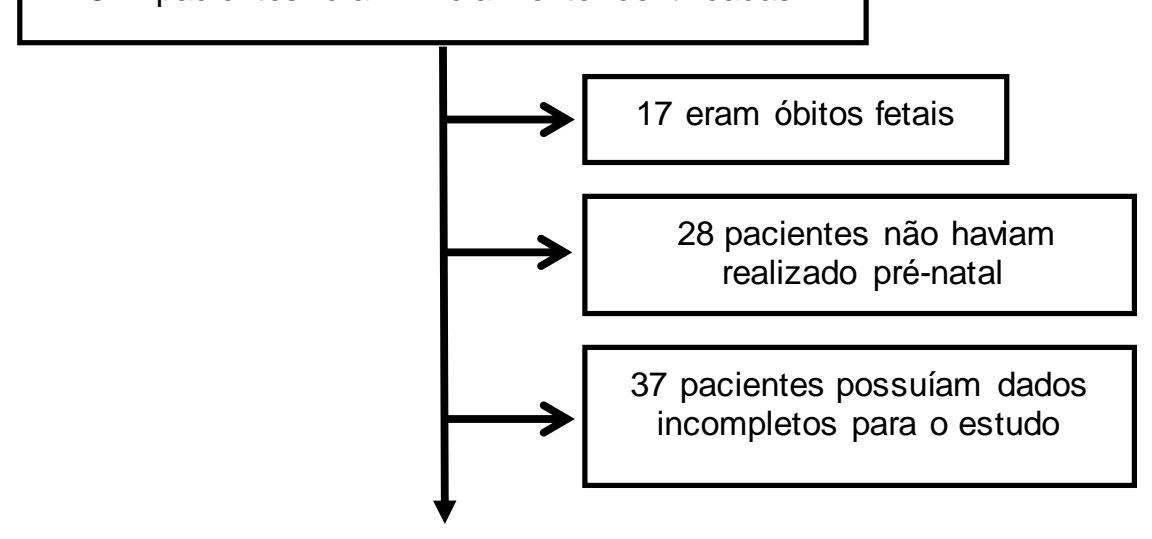

430 pacientes foram analisadas no estudo

Figura 2. Causas de exclusão de pacientes do grupo de gestações únicas.

Os critérios de elegibilidade do grupo caso (gestações gemelares) foram: gestação múltipla com dois fetos, IG confiável (calculada a partir da data da última menstruação e confirmada por ultrassom obstétrico realizado até a 20ª semana), 
seguimento pré-natal e resolução da gestação no HCFMRP-USP, assistência neonatal realizada no HCFMRP-USP. Os critérios de exclusão foram: anomalias estruturais ou cromossômicas diagnosticadas no período neonatal, seguimento prénatal inadequado, impossibilidade de aquisição dos dados de importância nos prontuários médicos. A IG considerada foi a calculada pela biometria do maior feto. A corionicidade foi determinada, no primeiro trimestre, pela visibilização de duas placentas separadas ou pela presença do "sinal do lâmbda", quando estas se encontravam justapostas. Caso a corionicidade fosse determinada no segundo trimestre, foram consideradas DC as gestações com visibilização de placentas separadas ou com sexos fetais discordantes. Caso houvesse dúvida sobre a corionicidade da gestação, esta seria considerada MC. No grupo controle (gestações com fetos únicos) foram incluídas pacientes com gestações únicas, IG confiável (calculada a partir da data da última menstruação e confirmada por ultrassom obstétrico realizado até a $20^{\underline{a}}$ semana), seguimento pré-natal e resolução da gestação no HCFMRP-USP, assistência neonatal realizada no HCFMRP-USP. Os critérios de exclusão foram os mesmos do grupo caso.

\section{Desfechos e definições}

Desfechos primários: resultado adverso perinatal.

Foram considerados como resultado adverso perinatal: óbito fetal em gestação com mais de 20 semanas, índice de Apgar < 7, no primeiro e/ou quinto minuto de vida; morbidade neonatal composta grave, óbito neonatal precoce (nos primeiros 28 dias de vida), hipoglicemia e icterícia. Como o serviço de Neonatologia do local de estudo é um membro da Rede Vermont Oxford, os critérios diagnósticos para cada uma dessas intercorrências neonatais foram os estabelecidos pela rede (Horbar, 1999).

1. Morbidade neonatal composta grave foi definida por um conjunto contendo um ou mais dos seguintes diagnósticos:

a) Hemorragia intracraniana (HIC). Foram consideradas HIC diagnosticadas em exames de imagem (ultrassonografia, tomografia computadorizada ou ressonância magnética) realizados até 0 28을 dia, grau III (hemorragia 
intraventricular, com dilatação dos ventrículos) ou IV (hemorragia intraparenquimatosa) (Lopriore et al., 2012);

b) Leucomalácia periventricular (LMPV). Foi considerada grave a leucomalácia periventricular cística ( $\geq$ grau II) (de Vries et al., 1992; Lopriore et al., 2012);

c) Encefalopatia hipóxico-isquêmica $(\mathrm{EHI})$. Esse diagnóstico requer a presença dos três seguintes critérios: achados de encefalopatia dentro das primeiras 72 horas (três ou mais destes: nível anormal de consciência, tônus muscular anormal, reflexos tendíneos profundos anormais, convulsões, reflexo de Moro anormal, sucção anormal, padrão respiratório anormal, anormalidades oculomotoras ou pupilares); ausência de causa infecciosa, anomalias congênitas ou erro inato do metabolismo que justifiquem o quadro; suporte de exames complementares (três ou mais destes: Apgar $\leq 5$ no $5^{\circ}$ minuto, $\mathrm{pH}$ de sangue de cordão < 7.00; evidência de falência de múltiplos órgãos, suspeita de sofrimento fetal agudo (SFA) na cardiotocografia ou perfil biofísico fetal ou Doppler com diástole reversa de artéria umbilical fetal; achado de isquemia ou edema cerebral em exames de imagem do $\mathrm{RN}$ até 7 dias do nascimento; eletroencefalograma anormal) (Horbar, 1999);

d) Enterocolite necrosante (ECN). Para o diagnóstico foi considerado a existência de pelo menos um critério clínico (aspiração gástrica biliosa ou êmese, distensão abdominal e/ou sangue oculto ou grosseiro nas fezes) associado a pelo menos um critério radiológico (pneumatose intestinal, gás hepatobiliar e/ou pneumoperitônio) (Horbar, 1999);

e) Síndrome do desconforto respiratório (SDR). A variável foi definida como quadro de insuficiência respiratória que requer ventilação mecânica (incluindo pressão positiva contínua nas vias aéreas) e suplementação com oxigênio nas primeiras 24 horas, associado a achados radiológicos típicos (Lopriore et al., 2012);

f) Sepse: quadro clínico associado à hemocultura positiva ou meningite confirmada por meio de cultura de líquido cefalorraquidiano, dentro de 72 horas após o nascimento (Horbar, 1999; Barrett et al., 2013).

2. Hipoglicemia foi definida como qualquer medida de glicose abaixo de $40 \mathrm{mg} / \mathrm{dl}$ nas primeiras $24 \mathrm{~h}$. 
3. Icterícia. Embora este tenha sido um achado comum, foram apenas considerados para análise deste desfecho aqueles $\mathrm{RN}$ que receberam como tratamento, pelo menos, fototerapia.

As seguintes variáveis foram utilizadas na análise como potenciais fatores de risco para os desfechos neonatais:

1. Variáveis maternas:

- Idade ( $\leq 19$ anos, $20-35$ ou $\geq 35$ anos);

- Cor da pele (branca ou não branca);

- Estado civil (com companheiro, sem companheiro);

- Atividade profissional (trabalha fora ou dona de casa)

- Tabagismo (sim ou não);

- Presença de hipertensão arterial, prévia ou de aparecimento na gestação (sim ou não);

- Presença de Diabetes mellitus prévio (sim ou não);

- Obesidade representada por $I M C \geq 30 \mathrm{~kg} / \mathrm{m}^{2}$ (sim ou não).

2. Variáveis relacionadas à gestação:

- Paridade (primigesta ou outra paridade);

- Antecedente de prematuridade representado por parto prévio antes da $37^{a}$ semana (sim ou não);

- RCIU (sim ou não);

- Centralização hemodinâmica fetal (sim ou não);

- Suspeita de SFA (sim ou não);

- Corioamniorrexe prematura PT (sim ou não);

- Oligohidrâmnio (excluída corioamniorrexe) diagnosticado pela medida do maior bolsão de líquido amniótico abaixo do percentil 5 para a IG (Magann et al., 2000);

- Polihidrâmnio diagnosticado pela medida do maior bolsão de líquido amniótico acima do percentil 95 para a IG (Magann et al., 2000);

- PPT antes da 28ª semana de IG (sim ou não);

- PPT entre 28 e 32 semanas de IG, incluindo a 28aㅗ (sim ou não);

- PPT entre 32 e 34 semanas de IG, incluindo a $32^{a}$ (sim ou não); 
- PPT em entre 34 e 37 semanas, incluindo ambos os extremos (sim ou não);

- Corticoindução da maturidade fetal com betametasona, entre 24 e 34 semanas (sim ou não). Considerou-se como resposta sim aquele caso em que se realizou, pelo menos, um ciclo completo (12 mg diárias, por dois dias consecutivos), dentro da última semana que antecedeu o parto.

- Tipo de parto (vaginal ou cesárea).

No caso da gestação gemelar, as variáveis restrição do crescimento intrauterino, centralização hemodinâmica fetal, SFA, corioamniorrexe prematura PT, oligohidrâmnio e polihidrâmnio foram consideradas como resposta sim quando pelo menos um dos fetos foi acometido pela intercorrência em questão. Além disso, apenas no caso das gestações gemelares, acrescentou-se como variável de risco para os desfechos a monocorionicidade (sim ou não).

\section{Análise estatística}

\section{Cálculo do $n$ amostral}

Levando-se em consideração um nível de significância de 5\%, poder do teste de $85 \%$ e que as taxas de fetos acometidos pela SDR agudo que receberam e não recebem corticóide no período anteparto são de 60 e 75\%, respectivamente, estimou-se um $n$ amostral de 174 recém-nascidos (www.lee.dante.br).

Os dados foram tabulados em uma planilha em Excel e em seguida foram importados para o programa SAS versão 9.3. Uma análise exploratória inicial foi realizada para verificar a distribuição das variáveis no estudo. As variáveis qualitativas foram descritas através de frequências absolutas e relativas.

\section{Análises e Modelos estatísticos}

Inicialmente, riscos relativos (RR) e intervalos de confiança $95 \%$ foram calculados para comparar as características gerais das gestações únicas e gemelares. Para investigar os desfechos, foram construídos modelos de regressão logística. O Odds Ratio (OR) será considerado como medida de tamanho de efeito para quantificar a relação entre as variáveis preditoras e os desfechos, considerando as gestações únicas e gemelares separadamente. Para verificar a 
presença de variáveis confundidoras serão ajustados modelos uni e multivariados. Foi adotado um nível de significância de 5\%. 


\section{RESULTADOS}


No presente estudo, foram analisados os dados coletados de 864 pacientes e seus 1298 filhos. Destas, 434 pacientes eram portadoras de gestações gemelares duplas e 430 possuíam gestações únicas. Com relação à corionicidade das gestações gemelares, 273 (62,9\%) eram DC e 161 (37,1\%) MC. A Tabela 1 exibe as características demográficas maternas, gestacionais e neonatais da população estudada.

Tabela 1. Características demográficas maternas, gestacionais e neonatais da população estudada.

\begin{tabular}{|c|c|c|c|}
\hline & $\begin{array}{c}\text { Gestação única } \\
\mathrm{n}(\%)\end{array}$ & $\begin{array}{c}\text { Gestação gemelar } \\
\mathrm{n}(\%)\end{array}$ & $\begin{array}{l}\text { Risco Relativo } \\
\text { (IC 95\%) }\end{array}$ \\
\hline \multicolumn{4}{|l|}{$\begin{array}{l}\text { Características maternas } \\
\text { ldade }\end{array}$} \\
\hline$\leq 19$ anos & $51(11,9)$ & $34(7,8)$ & $1,51(1,00-2,29)$ \\
\hline$\geq 35$ anos & $50(11,6)$ & $51(11,7)$ & $0,98(0,68-1,42)$ \\
\hline \multicolumn{4}{|l|}{ Cor da pele } \\
\hline Não branca & $155(36,0)$ & $114(26,3)$ & $1,37(1,12-1,68)$ \\
\hline \multicolumn{4}{|l|}{ Estado civil } \\
\hline Sem companheiro & $147(34,2)$ & $212(48,8)$ & $0,70(0,59-0,82)$ \\
\hline \multicolumn{4}{|l|}{ Profissão } \\
\hline Trabalha fora & $148(34,4)$ & $172(39,6)$ & $0,86(0,73-1,03)$ \\
\hline Tabagismo & $42(9,8)$ & $67(15,4)$ & $0,63(0,44-0,91)$ \\
\hline Diabetes mellitus & $34(7,9)$ & $6(1,4)$ & $5,72(2,42-13,48)$ \\
\hline Hipertensão arterial crônica & $102(23,7)$ & $28(6,4)$ & $3,68(2,47-5,46)$ \\
\hline Obesidade & $66(15,3)$ & $23(5,3)$ & $2,90(1,84-4,57)$ \\
\hline \multicolumn{4}{|l|}{ Características da gestação } \\
\hline Primigravidae & $206(47,9)$ & $200(46,1)$ & $1,03(0,83-1,12)$ \\
\hline Antecedente de prematuridade & $279(64,9)$ & $20(4,6)$ & $14,08(9,13-21,72)$ \\
\hline Corioamniorrexe prematura & $90(20,9)$ & $73(16,8)$ & $1,24(0,94-1,64)$ \\
\hline Trabalho de parto pré-termo & $256(59,5)$ & $263(60,6)$ & $0,98(0,88-1,10)$ \\
\hline DPPNI & $13(3,0)$ & $5(1,2)$ & $2,62(0,94-7,29)$ \\
\hline Placenta prévia & $9(2,1)$ & $4(0,9)$ & $2,27(0,70-7,32)$ \\
\hline Hipertensão gestacional/PE & $77(17,9)$ & $58(13,4)$ & $1,34(0,97-1,83)$ \\
\hline Diabetes gestacional & $21(4,9)$ & $34(7,8)$ & $0,62(0,36-1,06)$ \\
\hline $\mathrm{RCIU}$ & $53(12,3)$ & $94(10,8)$ & $1,14(0,88-1,49)$ \\
\hline Óbito fetal & $8(1,9)$ & $66(7,6)$ & $0,25(0,11-0,36)$ \\
\hline Analgesia de parto & $145(33,7)$ & $366(84,3)$ & $0,40(0,35-0,46)$ \\
\hline Parto cesárea & $195(45,3)$ & $269(62,0)$ & $0,73(0,64-0,84)$ \\
\hline Complicações puerperais & $28(6,5)$ & $46(10,6)$ & $0,61(0,39-0,96)$ \\
\hline \multicolumn{4}{|l|}{ Resultados neonatais } \\
\hline Parto pré-termo < 37 semanas & $236(54,9)$ & $578(66,6)$ & $0,82(0,69-0,98)$ \\
\hline Parto pré-termo < 32 semanas & $140(32,5)$ & $196(22,6)$ & $1,45(1,21-1,75)$ \\
\hline BPN $(<2500$ gramas $)$ & $199(46,3)$ & $567(65,3)$ & $0,71(0,63-0,79)$ \\
\hline Morbidade composta & $34(7,9)$ & $67(7,7)$ & $1,02(0,69-1,52)$ \\
\hline Apgar de $5^{\circ}$ minuto $<7$ & $48(11,2)$ & $115(13,2)$ & $0,84(0,61-1,15)$ \\
\hline Óbito neonatal & $36(8,3)$ & $44(5,0)$ & $1,65(1,08-2,52)$ \\
\hline
\end{tabular}


Com relação às características maternas, algumas diferenças significativas foram observadas entre as duas populações: as gestantes de fetos únicos foram mais frequentemente não brancas (RR: 1,37; IC95\% 1,12-1,68) e com prevalência de tabagismo $37 \%$ menor quando comparadas as gestantes com gemelares (RR: 0,63; IC $95 \%$ 0,44-0,91). Além disso, as gestantes com fetos únicos tinham, já no início da gestação, 5 vezes mais Diabetes mellitus (RR: 5,72; IC95\% 2,42-13,48), quase 4 vezes mais HAC (RR: 3,68; IC95\% 2,47-5,46) e quase 3 vezes mais obesidade (RR: 2,90; IC95\% 1,84-4,57). Outro dado interessante foi uma prevalência maior de mulheres sem companheiro entre aquelas com gestações gemelares.

$\mathrm{Na}$ Tabela 1, considerando os dois grupos, observaram-se também diferenças em relação às características da gestação e parto e resultados neonatais. Antecedente de prematuridade foi 14 vezes mais frequente na população de fetos únicos (RR: 14,08; IC95\% 9,13-21,72) e a probabilidade de óbito fetal foi $75 \%$ menor nesse grupo (RR: 0,25; IC95\% 0,11-0,36). Analgesia de parto foi $60 \%$ menos provável no grupo de fetos únicos (RR: 0,40; IC95\% 0,35-0,46), assim como 27\% menos provável foi o parto cesárea (RR: 0,73; IC95\% 0,64-0,84) e 40\% menos provável a existência de complicações puerperais (RR: 0,61; IC95\% 0,39-0,96). Quanto aos resultados neonatais, prematuridade abaixo de 37 semanas foi discretamente mais prevalente na população de fetos gemelares (RR: 0,82; IC95\% 0,69-0,98). Por outro lado, a prematuridade extrema foi mais frequente entre os fetos únicos (RR: 1,45; IC95\% 1,21-1,75), assim como o óbito neonatal (RR: 1,65; IC95\% 1,08-2,52). Porém, a prevalência de baixo peso ao nascer foi maior no grupo de RN gemelares (RR: 0,71; IC95\% 0,63-0,79).

A Tabela 2 mostra a influência das características maternas e relacionadas à gestação sobre o Apgar de $1^{\circ}$ minuto nos dois grupos estudados. Na análise do grupo de gestações únicas, observou-se que presença de SFA, prematuridade abaixo de 32 semanas e corticoindução aumentaram o risco do RN de Apgar $<7$ no 1 - minuto de vida. O parto vaginal parece ter um efeito positivo sobre a ocorrência deste resultado adverso. Quando avaliamos a população de RN gemelares, notouse que a presença de hipertensão e obesidade materna, IG ao nascimento maior 
que 34 semanas e corticoindução aumentaram a chance de melhores índices de Apgar. Além disso, RCIU e prematuridade abaixo de 32 semanas foram variáveis que aumentaram o risco de Apgar de $1^{\circ}$ minuto $<7$, assim como a realização de parto vaginal.

Tabela 2. Influência das características demográficas maternas e relacionadasà gestação sobre o Apgar de primeiro minuto dos recém-nascidos de gestações únicas e gemelares.

\begin{tabular}{|c|c|c|c|c|c|c|}
\hline \multirow[b]{2}{*}{ Covariáveis } & \multicolumn{3}{|c|}{ Gestação única } & \multicolumn{3}{|c|}{ Gestação gemelar } \\
\hline & $\begin{array}{c}\text { Apgar }>7 \\
\mathrm{n}(\%)\end{array}$ & $\begin{array}{c}\text { Apgar }<7 \\
\mathrm{n}(\%)\end{array}$ & OR (IC95\%) & $\begin{array}{c}\text { Apgar }>7 \\
\mathrm{n}(\%)\end{array}$ & $\begin{array}{c}\text { Apgar <7 } \\
\mathrm{n}(\%)\end{array}$ & OR (IC95\%) \\
\hline \multicolumn{7}{|l|}{$\begin{array}{l}\text { Características maternas } \\
\text { ldade }\end{array}$} \\
\hline $\begin{array}{l}\leq 19 \\
19-35 \\
\geq 35\end{array}$ & $\begin{array}{c}27(10,2) \\
207(78,4) \\
30(11,4)\end{array}$ & $\begin{array}{c}24(14,5) \\
122(73,5) \\
20(12,0)\end{array}$ & $\begin{array}{l}0,70(0,42-1,18) \\
1,07(0,95-1,19) \\
0,94(0,55-1,60)\end{array}$ & $\begin{array}{c}51(8,3) \\
495(80,8) \\
67(10,9)\end{array}$ & $\begin{array}{c}19(7,4) \\
201(78,8) \\
35(13,8)\end{array}$ & $\begin{array}{l}0,12(0,67-1,85) \\
1,02(0,95-1,10) \\
0,79(0,54-1,16)\end{array}$ \\
\hline \multicolumn{7}{|l|}{ Cor da pele } \\
\hline Branca & $173(65,5)$ & $102(61,4)$ & $1,07(0,92-1,24)$ & $455(74,2)$ & $187(73,3)$ & $1,01(0,92-1,10)$ \\
\hline Não branca & $91(34,5)$ & $64(38,6)$ & $0,89(0,69-1,15)$ & $158(25,8)$ & $68(26,7)$ & $0,97(0,75-1,23)$ \\
\hline Com companheiro & $171(64,8)$ & $112(67,5)$ & $0,96(0,84-1,10)$ & $308(50,2)$ & $136(53,3)$ & $0,94(0,82-1,08)$ \\
\hline Sem companheiro & $93(35,2)$ & $54(32,5)$ & $1,08(0,82-1,42)$ & $305(49,8)$ & $119(46,7)$ & $1,07(0,91-1,24)$ \\
\hline \multicolumn{7}{|l|}{ Profissão } \\
\hline Não trabalha & $171(64,8)$ & $111(66,9)$ & $0,97(0,8$ & $373(60,8)$ & $151(59,2)$ & $1,03(0$, \\
\hline Trabalha fora & $93(35,2)$ & $55(33,1)$ & $1,06(0,81-1,39)$ & $240(39,1)$ & $104(40,8)$ & $0,96(0,80-1,15)$ \\
\hline Tabagismo & $29(11,0)$ & $13(7,8)$ & $1,40(0,75-2,62)$ & $98(16,0)$ & $36(14,1)$ & $1,13(0,80-1,61)$ \\
\hline Diabetes mellitus & $21(7,9)$ & $13(7,8)$ & $1,02(0,52-1,97)$ & $6(1,0)$ & $6(2,4)$ & $0,42(0,14-1,28)$ \\
\hline Hipertensão arterial & $58(22,0)$ & $44(26,5)$ & $0,83(0,59-1,16)$ & $47(7,7)$ & $9(3,5)$ & $2,17(1,08-4,37)$ \\
\hline $\begin{array}{l}\text { Obesidade } \\
\text { Dados da gestação }\end{array}$ & $42(15,9)$ & $24(14,5)$ & $1,10(0,69-1,75)$ & $40(6,5)$ & $6(2,4)$ & $2,77(1,19-6,46)$ \\
\hline Primigravidae & 122 & $0,6)$ & ,11) & $45,0)$ & $126(49,4)$ & 1,09 \\
\hline Antecedente de PPT & $171(64,8)$ & $108(65,1)$ & $0,99(0,86-1,15)$ & $27(4,4)$ & $13(5,1)$ & $0,86(0,45-1,65)$ \\
\hline RCIU & $27(10,2)$ & $26(15,7)$ & $0,65(0,40-1,08)$ & $47(7,7)$ & $47(18,4)$ & $0,42(0,29-0,61)$ \\
\hline Centralização hemodinâmica & $17(6,4)$ & $19(11,5)$ & $0,56(0,30-1,05)$ & $48(7,8)$ & $22(8,6)$ & $0,91(0,56-1,47)$ \\
\hline SFA & $14(5,3)$ & $24(14,5)$ & $0,37(0,19-0,69)$ & $63(10,3)$ & $31(12,2)$ & $0,85(0,56-1,27)$ \\
\hline Oligohidrâmnio & $13(4,9)$ & $15(9,0)$ & $0,55(0,27-1,12)$ & $15(2,5)$ & $11(4,3)$ & $0,57(0,26-1,22)$ \\
\hline Polihidrâmnio & $3(1,1)$ & $5(3,0)$ & $0,38(0,09-1,56)$ & $3(0,5)$ & $5(2,0)$ & $0,25(0,06-1,04)$ \\
\hline \multicolumn{7}{|l|}{ Prematuridade } \\
\hline Faixa um (34 |-| 37 sem) & $125(47,3)$ & $38(22,9)$ & $2,07(1,52-2,81)$ & $221(36,0)$ & $51(20,0)$ & $1,80(1,38-2,35)$ \\
\hline Faixa dois (32 |-34 sem) & $48(18,2)$ & $25(15,1)$ & $1,20(0,77-1,88)$ & $84(13,7)$ & $34(13,3)$ & $1,03(0,71-1,49)$ \\
\hline Faixa três (28 |- 32 sem) & $37(14,0)$ & $49(29,5)$ & $0,47(0,32-0,69)$ & $59(9,6)$ & $55(21,6)$ & $0,45(0,32-0,63)$ \\
\hline Faixa quatro (<28 sem) & $6(2,3)$ & $48(28,9)$ & $0,08(0,03-0,18)$ & $14(2,3)$ & $68(26,7)$ & $0,09(0,05-0,15)$ \\
\hline Corticoindução & $105(39,8)$ & $83(50,0)$ & $0,79(0,64-0,98)$ & $427(69,7)$ & $133(52,2)$ & $1,34(1,17-1,52)$ \\
\hline Parto vaginal & $164(62,1)$ & $71(42,8)$ & $1,45(1,19-1,77)$ & $209(34,1)$ & $119(46,7)$ & $0,73(0,61-0,86)$ \\
\hline Monocorionicidade & -- & -- & - & $227(37,0)$ & $95(37,2)$ & $0,99(0,82-1,20)$ \\
\hline
\end{tabular}

$\mathrm{Na}$ análise multivariada (Tabela 3) de gestações únicas, para Apgar de $1^{\circ}$ minuto, filhos de mães que não tiveram Diabetes ou doença hipertensiva têm risco menor de Apgar $<7$ no $1^{\circ}$ minuto. O SFA foi confirmado como fator de risco para esse desfecho, assim como a prematuridade em todas as faixas de IG inferiores a 37 semanas. Por outro lado, a corticoindução foi afastada como fator de risco, como 
havia sido visto na Tabela 2 e o parto vaginal permaneceu como fator protetor de Apgar $<7$ no $1^{\circ}$ minuto. Nas gestações gemelares, a RCIU foi confirmada como fator de risco para Apgar de 1은 minuto $<7$, da mesma forma que nascer em IG inferiores a 34 semanas e de parto vaginal. Essa tabela também mostra que a corticoindução permaneceu como fator protetor desse desfecho entre os RN gemelares.

Tabela 3. Efeito das características demográficas maternas e relacionadas à gestação sobre o Apgar de primeiro minuto dos recém-nascidos de gestações únicas e gemelares (análise multivariada).

\begin{tabular}{|c|c|c|c|c|c|c|}
\hline \multirow[b]{2}{*}{ VARIAVEIS } & \multicolumn{3}{|c|}{ Gestação única } & \multicolumn{3}{|c|}{ Gestacão gemelar } \\
\hline & OR & IC $95 \%$ & $p$ valor & OR & IC $95 \%$ & $p$ valor \\
\hline Idade ( $\leq 19$ anos $X 20-34$ anos) & 0,86 & $0,31-2,43$ & 0,96 & 0,47 & $0,21-1,07$ & 0,36 \\
\hline Idade $(\geq 35$ anos $\times 20-34$ anos $)$ & 0,72 & $0,35-1,49$ & 0,35 & 0,91 & $0,54-1,52$ & 0,06 \\
\hline Cor da pele (branca Xnão branca) & 0,89 & $0,54-1,46$ & 0,64 & 1,06 & $0,71-1,57$ & 0,77 \\
\hline Estado civil (com Xsem companheiro) & 0,88 & $0,53-1,47$ & 0,63 & 1,09 & $0,77-1,54$ & 0,62 \\
\hline Profissão (não Xsim) & 0,94 & $0,58-1,54$ & 0,82 & 0,94 & $0,66-1,33$ & 0,72 \\
\hline Tabagismo (não Xsim) & 0,57 & $0,22-1,46$ & 0,24 & 1,12 & $0,70-1,80$ & 0,64 \\
\hline Diabetes mellitus (não Xsim) & 0,29 & $0,11-0,77$ & 0,01 & 0,22 & $0,03-1,74$ & 0,15 \\
\hline Hipertensão arterial (não Xsim) & 0,31 & $0,13-0,73$ & 0,01 & 2,40 & $0,32-18,26$ & 0,39 \\
\hline Obesidade (não Xsim) & 0,78 & $0,36-1,69$ & 0,53 & 3,28 & $0,63-17,12$ & 0,16 \\
\hline Primigravidae (não Xsim) & 0,72 & $0,35-1,47$ & 0,37 & 0,73 & $0,51-1,06$ & 0,10 \\
\hline Prematuridade prévia (não Xsim) & 1,33 & $0,66-2,67$ & 0,42 & 0,91 & $0,38-2,13$ & 0,82 \\
\hline RCIU (não Xsim) & 0,72 & $0,27-1,94$ & 0,52 & 0,52 & $0,28-0,99$ & 0,04 \\
\hline Centralização hemodinâmica (não Xsim) & 1,49 & $0,47-4,68$ & 0,49 & 1,12 & $0,53-2,32$ & 0,77 \\
\hline SFA (não Xsim) & 0,31 & $0,13-0,74$ & 0,008 & 1,18 & $0,62-2,44$ & 0,61 \\
\hline Oligohidrâmnio (não Xsim) & 0,46 & $0,15-1,38$ & 0,17 & 0,53 & $0,21-1,34$ & 0,18 \\
\hline Polihidrâmnio (não Xsim) & 0,24 & $0,04-1,34$ & 0,10 & 0,58 & $0,11-3,10$ & 0,52 \\
\hline IG ao nascer $(34-37$ sem $X>37$ sem $)$ & 2,76 & $1,08-7,08$ & 0,03 & 1,21 & $0,78-1,88$ & 0,40 \\
\hline IG ao nascer $(32-34 \mathrm{sem} X>37 \mathrm{sem})$ & 5,66 & $1,92-16,64$ & 0,002 & 1,95 & $1,16-3,29$ & 0,01 \\
\hline IG ao nascer $(28-32$ sem $X>37$ sem $)$ & 13,87 & $4,90-39,24$ & $<0,0001$ & 4,95 & $2,96-8,27$ & $<0,0001$ \\
\hline IG ao nascer $(<28 \mathrm{sem} X>37 \mathrm{sem})$ & 82,35 & $23,94-283,32$ & $<0,0001$ & 16,98 & $8,80-32,78$ & $<0,0001$ \\
\hline Corticoindução (sim X não) & 0,62 & $0,36-1,09$ & 0,09 & 0,48 & $0,33-0,69$ & $<0,0001$ \\
\hline Parto vaginal (sim $X$ não) & 0,37 & $0,22-0,66$ & 0,0006 & 1,51 & $1,04-2,17$ & 0,03 \\
\hline Monocorionicidade (DC XMC) & . & -- & . & 1,27 & $0,89-1,82$ & 0,19 \\
\hline
\end{tabular}

OR: odds ratio; IC: intervalo de confiança; RCIU: restrição do crescimento intrauterino; SFA: sof rimento fetal agudo; sem: semanas; DC: dicorionicidade; MC: monocorionicidade.

A Tabela 4 demonstra a influência das variáveis sobre o Apgar de 5ำ minuto nos dois grupos estudados. $\mathrm{Na}$ análise das gestações únicas, observou-se que mães adolescentes, SFA e prematuridade abaixo de 28 semanas aumentaram o risco de Apgar $<7$ no $5^{\circ}$ minuto. Da mesma forma que na Tabela 2, ter mais de 34 semanas reduziu o risco do RN ter Apgar de 5o minuto $<7$. Considerando os resultados dos $\mathrm{RN}$ gemelares, observou-se que $\mathrm{RN}$ com diagnóstico de $\mathrm{RCIU}$, polihidrâmnio, IG ao nascimento $<32$ semanas e que nasceram de parto vaginal apresentaram maiores probabilidades de Apgar $<7$ no $5^{\circ}$ minuto, assim como filhos de mulheres que trabalhavam fora. A corticoindução parece ter um efeito protetor sobre esse resultado adverso. 
Tabela 4. Influência das características demográficas maternas e relacionadas à gestação sobre o Apgar de quinto minuto dos recém-nascidos de gestações únicas e gemelares.

\begin{tabular}{|c|c|c|c|c|c|c|}
\hline \multirow[b]{2}{*}{ Covariáveis } & \multicolumn{3}{|c|}{ Gestação única } & \multicolumn{3}{|c|}{ Gestação gemelar } \\
\hline & $\begin{array}{c}\text { Apgar }>7 \\
n(\%)\end{array}$ & $\begin{array}{c}\text { Apgar }<7 \\
\mathrm{n}(\%)\end{array}$ & OR (IC95\%) & $\begin{array}{c}\text { Apgar }>7 \\
n(\%)\end{array}$ & $\begin{array}{c}\text { Apgar }<7 \\
n(\%)\end{array}$ & OR (IC95\%) \\
\hline \multicolumn{7}{|l|}{$\begin{array}{l}\text { Características maternas } \\
\text { Idade }\end{array}$} \\
\hline$\leq 19$ & $40(10,5)$ & $11(22,9)$ & $0,46(0,25-0,83)$ & $56(7,4)$ & $14(12,2)$ & $0,61(0,35-1,06)$ \\
\hline$\overline{19}-35$ & $295(77,2)$ & $34(70,8)$ & $1,09(0,90-1,32)$ & $613(81,4)$ & $83(72,2)$ & $1,12(1,00-1,27)$ \\
\hline$\geq 35$ & $47(12,3)$ & $3(6,3)$ & $1,97(0,64-6,08)$ & $84(11,2)$ & $18(15,6)$ & $0,61(0,44-1,14)$ \\
\hline \multicolumn{7}{|l|}{ Cor da pele } \\
\hline Branca & $249(65,2)$ & $26(54,2)$ & $1,20(0,92-1,58)$ & $555(73,7)$ & $87(75,7)$ & $0,97(0,87-1,09)$ \\
\hline Não branca & $133(34,8)$ & $22(45,8)$ & $0,76(0,54-1,06)$ & $198(26,3)$ & $28(24,3)$ & $1,08(0,76-1,52)$ \\
\hline \multicolumn{7}{|l|}{ Estado civil } \\
\hline Com companheiro & $253(66,2)$ & $30(62,5)$ & $1,06(0,84-1,33)$ & $390(51,8)$ & $54(47,0)$ & $1,10(0,89-1,36)$ \\
\hline Sem companheiro & $129(33,8)$ & $18(37,5)$ & $0,90(0,60-1,33)$ & $363(48,2)$ & $61(53,0)$ & $0,91(0,75-1,10)$ \\
\hline \multicolumn{7}{|l|}{ Profissão } \\
\hline Não trabalha & $245(64,1)$ & $37(77,1)$ & $0,83(0,70-1,00)$ & $465(61,8)$ & $59(51,3)$ & $1,20(0,99-1,45)$ \\
\hline Trabalha fora & $137(35,9)$ & $11(22,9)$ & $1,56(0,92-2,67)$ & $288(38,2)$ & $56(48,7)$ & $0,79(0,64-0,97)$ \\
\hline Tabagismo & $37(9,7)$ & $5(10,4)$ & $0,93(0,38-2,25)$ & $118(15,7)$ & $16(13,9)$ & $1,12(0,69-1,83)$ \\
\hline Diabetes mellitus & $33(8,6)$ & $1(2,1)$ & $4,15(0,58-29,63)$ & $9(1,2)$ & $3(2,6)$ & $0,46(0,13-1,67)$ \\
\hline Hipertensão arterial crônica & $91(23,8)$ & $11(22,9)$ & $1,03(0,60-1,80)$ & $53(7,0)$ & $3(2,6)$ & $2,70(0,85-8,49)$ \\
\hline Obesidade & $60(15,7)$ & $6(12,5)$ & $1,25(0,57-2,75)$ & $45(6,0)$ & $1(0,9)$ & $6,87(0,95-49,37)$ \\
\hline \multicolumn{7}{|l|}{ Dados da gestação } \\
\hline Primigravidae & $180(47,1)$ & $26(54,1)$ & $0,87(0,66-1,15)$ & $341(45,3)$ & $61(53,0)$ & $0,85(0,71-1,03)$ \\
\hline Antecedente de PPT & $246(64,4)$ & $33(68,7)$ & $0,94(0,76-1,14)$ & $34(4,5)$ & $6(5,2)$ & $0,86(0,37-2,02)$ \\
\hline RCIU & $47(12,3)$ & $6(12,5)$ & $0,98(0,44-2,18)$ & $65(8,6)$ & $29(25,2)$ & $0,34(0,23-0,51)$ \\
\hline Centralização hemodinâmica & $32(8,4)$ & $4(8,3)$ & $1,00(0,37-2,72)$ & $58(7,7)$ & $12(10,4)$ & $0,74(0,40-1,33)$ \\
\hline SFA & $30(7,8)$ & $8(16,7)$ & $0,47(0,22-0,97)$ & $77(10,2)$ & $17(14,8)$ & $0,69(0,42-1,13)$ \\
\hline Oligohidrâmnio & $23(6,0)$ & $5(10,4)$ & $0,58(0,23-1,45)$ & $20(2,7)$ & $6(5,2)$ & $0,51(0,21-1,24)$ \\
\hline Polihidrâmnio & $7(1,8)$ & $1(2,1)$ & $0,88(0,11-6,99)$ & $4(0,5)$ & $4(3,5)$ & $0,15(0,04-0,60)$ \\
\hline \multicolumn{7}{|l|}{ Prematuridade } \\
\hline Faixa um (34 |-| 37 sem) & $155(40,6)$ & $8(16,7)$ & $2,43(1,27-4,64)$ & $259(34,4)$ & $13(11,3)$ & $3,04(1,80-5,12)$ \\
\hline Faixa dois (32|-34 sem) & $69(18,1)$ & $4(8,3)$ & $2,17(0,83-5,67)$ & $106(14,1)$ & $12(10,4)$ & $1,34(0,77-2,37)$ \\
\hline Faixa três (28|-32 sem) & $76(19,9)$ & $10(20,8)$ & $0,95(0,53-1,71)$ & $92(12,2)$ & $22(19,1)$ & $0,63(0,42-0,97)$ \\
\hline Faixa quatro $(<28 \mathrm{sem})$ & $28(7,3)$ & $26(54,2)$ & $0,13(0,08-0,21)$ & $36(4,8)$ & $46(40,0)$ & $0,12(0,08-0,18)$ \\
\hline Corticoindução & $170(44,5)$ & $18(37,5)$ & $1,19(0,81-1,74)$ & $516(68,5)$ & $44(38,3)$ & $1,79(1,41-2,27)$ \\
\hline Monocorionicidade & -- & -- & -- & $278(36,9)$ & $44(38,3)$ & $0,96(0,75-1,24)$ \\
\hline Parto vaginal & $213(55,8)$ & $22(45,8)$ & $1,21(0,88-1,67)$ & $265(35,2)$ & $63(54,8)$ & $0,64(0,53-0,79)$ \\
\hline
\end{tabular}

OR: odds ratio; PPT: parto pré-termo; RCIU: restrição do crescimento intrauterino; SFA: sof rimento fetal agudo; sem: semanas.

A análise multivariada da Tabela 5 mostra que mães que não fumam e não têm hipertensão têm risco menor de RN com Apgar de 5ํ minuto $<7$. O SFA e prematuridade abaixo de 32 semanas permaneceram como fatores de risco deste desfecho. Além disso, a corticoindução reduziu o risco de Apgar $<7$ no 5 minuto entre $\mathrm{RN}$ únicos. $\mathrm{Na}$ análise dos $\mathrm{RN}$ gemelares, ter mãe que trabalha fora permaneceu como fator de risco para Apgar $<7$ no 5ํㅡㄴ minuto, assim como Diabetes materno. Ainda, RCIU, prematuridade inferior a 32 semanas e parto vaginal também foram confirmadas como variáveis de risco, da mesma forma que corticoindução permaneceu como fator protetor para esse desfecho. 
Tabela 5. Efeito das características demográficas maternas e relacionadas à gestação sobre o Apgar de quinto minuto dos recém-nascidos de gestações únicas e gemelares (análise multivariada).

\begin{tabular}{|c|c|c|c|c|c|c|}
\hline \multirow[b]{2}{*}{ VARIÁVEIS } & \multicolumn{3}{|c|}{ Gestação única } & \multicolumn{3}{|c|}{ Gestação gemelar } \\
\hline & OR & IC $95 \%$ & $p$ valor & OR & IC $95 \%$ & $p$ valor \\
\hline Idade ( $\leq 19$ anos X $20-34$ anos) & 2,20 & $0,44-11,03$ & 0,27 & 1,03 & $0,39-2,73$ & 0,71 \\
\hline Idade ( $\geq 35$ anos $\times 20-34$ anos) & 1,26 & $0,35-4,55$ & 0,71 & 0,77 & $0,40-1,49$ & 0,32 \\
\hline Cor da pele (branca X não branca) & 0,68 & $0,33-1,39$ & 0,29 & 1,28 & $0,75-2,17$ & 0,36 \\
\hline Estado civil (com X sem companheiro) & 0,87 & $0,40-1,91$ & 0,73 & 0,69 & $0,43-1,11$ & 0,13 \\
\hline Profissão (não $X$ sim) & 1,24 & $0,57-2,69$ & 0,58 & 0,48 & $0,29-0,77$ & 0,002 \\
\hline Tabagismo (não Xsim) & 0,21 & $0,06-0,76$ & 0,02 & 1,23 & $0,64-2,37$ & 0,53 \\
\hline Diabetes mellitus (não X sim) & 0,71 & $0,10-4,81$ & 0,72 & 0,02 & $0,01-0,59$ & 0,02 \\
\hline Hipertensão arterial (não X sim) & 0,23 & $0,06-0,94$ & 0,04 & 0,25 & $0,01-2,26$ & 0,45 \\
\hline Obesidade (não Xsim) & 0,37 & $0,11-1,27$ & 0,12 & 1,15 & $0,15-8,75$ & 0,89 \\
\hline Primigravidae (não X sim) & 0,96 & $0,35-2,65$ & 0,94 & 0,76 & $0,45-1,25$ & 0,29 \\
\hline Prematuridade prévia (não X sim) & 1,07 & $0,38-3,00$ & 0,90 & 1,04 & $0,35-3,09$ & 0,94 \\
\hline RCIU (não X sim) & 1,08 & $0,22-5,39$ & 0,92 & 0,40 & $0,19-0,85$ & 0,01 \\
\hline Centralização hemodinâmica (não X sim) & 1,29 & $0,22-7,42$ & 0,77 & 0,96 & $0,37-2,43$ & 0,92 \\
\hline SFA (não X sim) & 0,29 & $0,09-0,93$ & 0,03 & 0,89 & $0,41-1,94$ & 0,77 \\
\hline Oligohidrâmnio (não X sim) & 0,23 & $0,05-1,03$ & 0,06 & 0,58 & $0,19-1,68$ & 0,31 \\
\hline Polihidrâmnio (não Xsim) & 0,30 & $0,04-2,50$ & 0,26 & 0,34 & $0,05-2,14$ & 0,25 \\
\hline IG ao nascer (34 - 37 sem $X>37$ sem $)$ & 8,01 & $0,62-103,05$ & 0,10 & 0,59 & $0,28-1,18$ & 0,13 \\
\hline IG ao nascer $(32-34$ sem $X>37$ sem $)$ & 12,90 & $0,85-195,76$ & 0,07 & 1,21 & $0,58-2,52$ & 0,60 \\
\hline IG ao nascer (28 - 32 sem $X>37$ sem $)$ & 27,62 & $2,08-366,06$ & 0,01 & 2,88 & $1,45-5,72$ & 0,002 \\
\hline IG ao nascer (<28 sem $X>37$ sem $)$ & 183,98 & $13,71 \rightarrow 999,9$ & $<0,0001$ & 12,39 & $6,40-23,99$ & $<0,0001$ \\
\hline Corticoindução (sim X não) & 0,33 & $0,15-0,74$ & 0,007 & 0,31 & $0,19-0,52$ & $<0,0001$ \\
\hline Parto vaginal (sim X não) & 0,47 & $0,21-1,07$ & 0,07 & 1,85 & $1,11-3,09$ & 0,01 \\
\hline Monocorionicidade (DC XMC) & -- & -- & & 1,37 & $0,84-2,24$ & 0,20 \\
\hline
\end{tabular}

OR: odds ratio; IC: intervalo de confiança; RCIU: restrição do crescimento intrauterino; SFA: sofrimento fetal agudo; sem: semanas; DC: dicorionicidade; MC: monocorionicidade.

A Tabela 6 exibe o efeito das variáveis sobre a morbidade composta dos RN. Apesar de a análise ficar prejudicada para algumas das variáveis com prevalência nula, dados interessantes podem ser extraídos da tabela. Considerando as gestações únicas, notou-se que o único parâmetro que aumenta o risco de morbidade composta é a prematuridade <28 semanas. Mas, apesar de não conseguir quantificar risco, as prevalências de RN que não desenvolveram morbidade em IG >32 semanas foram relevantes. Na análise das gestações gemelares, RN que tiveram diagnósticos como RCIU, centralização hemodinâmica e SFA parecem apresentar maior risco de morbidade composta, assim como RN PT com menos de 32 semanas. Outro dado importante é a monocorionicidade como fator de risco para morbidade composta. Por outro lado, RN com IG >34 semanas têm probabilidade maior de não apresentarem esse resultado adverso. 
Tabela 6. Influência das características demográficas maternas e relacionadas à gestação sobre morbidade composta dos recém-nascidos de gestações únicas e gemelares.

\begin{tabular}{|c|c|c|c|c|c|c|}
\hline \multirow{3}{*}{ Covariáveis } & \multicolumn{3}{|c|}{ Gestação única } & \multicolumn{3}{|c|}{ Gestação gemelar } \\
\hline & Não & Sim & OR (IC95\%) & Não & Sim & OR (IC95\%) \\
\hline & $n(\%)$ & $n(\%)$ & & $n(\%)$ & $n(\%)$ & \\
\hline \multicolumn{7}{|l|}{$\begin{array}{l}\text { Características maternas } \\
\text { Idade }\end{array}$} \\
\hline$<19$ & $47(11,9)$ & $4(11,8)$ & $1,00(0,38-2,63)$ & $63(7,9)$ & $7(10,4)$ & $0,76(0,24-3,14)$ \\
\hline $19-35$ & $300(75,8)$ & $29(85,3)$ & $0,89(0,76-1,03)$ & $646(80,6)$ & $50(74,6)$ & $1,08(0,88-2,78)$ \\
\hline$>35$ & $49(12,4)$ & $1(2,9)$ & $4,20(0,60-29,53)$ & $92(11,5)$ & $10(14,9)$ & $0,77(0,27-2,12)$ \\
\hline \multicolumn{7}{|l|}{ Cor da pele } \\
\hline Branca & $253(63,9)$ & $22(64,7)$ & $0,98(0,76-1,28)$ & $591(73,8)$ & $51(76,1)$ & $0,97(0,84-1,11)$ \\
\hline Não branca & $143(36,1)$ & $12(35,3)$ & $1,02(0,64-1,64)$ & $210(26,2)$ & $16(23,9)$ & $1,09(0,70-1,71)$ \\
\hline \multicolumn{7}{|l|}{ Estado civil } \\
\hline Com companheiro & $257(64,9)$ & $26(76,5)$ & $0,85(0,69-1,04)$ & $402(50,2)$ & $42(62,7)$ & $0,80(0,66-1,00)$ \\
\hline Sem companheiro & $139(35,1)$ & $8(23,5)$ & $1,49(0,80-2,77)$ & $399(49,8)$ & $25(37,3)$ & $1,33(0,97-1,83)$ \\
\hline \multicolumn{7}{|l|}{ Profissão } \\
\hline Não trabalha & $258(65,1)$ & $24(70,6)$ & $0,92(0,73-1,16)$ & $486(60,7)$ & $38(56,7)$ & $1,06(0,86-1,33)$ \\
\hline Trabalha fora & $138(34,8)$ & $10(29,4)$ & $1,18(0,69-2,02)$ & $315(39,3)$ & $29(43,3)$ & $0,90(0,68-1,21)$ \\
\hline Tabagismo & $41(10,3)$ & $1(2,9)$ & $3,52(0,50-24,80)$ & $122(15,2)$ & $12(17,9)$ & $0,85(0,50-1,46)$ \\
\hline Diabetes mellitus & $34(8,5)$ & $0(0,0)$ & -- & $12(1,5)$ & $0(0,0)$ & -- \\
\hline Hipertensão arterial crônica & $94(23,7)$ & $8(23,5)$ & $1,01(0,54-1,89)$ & $52(6,5)$ & $4(6,0)$ & $1,09(0,41-2,91)$ \\
\hline Obesidade & $64(16,2)$ & $2(5,9)$ & $2,74(0,70-10,74)$ & $42(5,2)$ & $4(6,0)$ & $0,87(0,32-2,38)$ \\
\hline \multicolumn{7}{|l|}{ Dados da gestacão } \\
\hline Primigravidae & $187(47,2)$ & $19(55,9)$ & $0,84(0,62-1,16)$ & $375(46,8)$ & $27(40,3)$ & $1,16(0,86-1,57)$ \\
\hline Antecedente de PPT & $255(64,4)$ & $24(70,6)$ & $0,91(0,73-1,14)$ & $35(4,4)$ & $5(7,5)$ & $0,59(0,24-1,44)$ \\
\hline RCIU & $51(12,9)$ & $2(5,9)$ & $2,19(0,55-8,60)$ & $76(9,5)$ & $18(26,9)$ & $0,35(0,22-0,55)$ \\
\hline Centralização hemodinâmica & $34(8,6)$ & $2(5,9)$ & $1,46(0,37-5,82)$ & $60(7,5)$ & $10(14,9)$ & $0,50(0,27-0,93)$ \\
\hline SFA & $36(9,1)$ & $2(5,9)$ & $1,54(0,39-6,14)$ & $77(9,6)$ & $17(25,4)$ & $0,38(0,24-0,60)$ \\
\hline Oligohidrâmnio & $27(6,8)$ & $1(2,9)$ & $2,31(0,32-16,54)$ & $23(2,9)$ & $3(4,5)$ & $0,64(0,20-2,08)$ \\
\hline Polihidrâmnio & $8(2,0)$ & $0(0,0)$ & -- & $8(1,0)$ & $0(0,0)$ & -- \\
\hline \multicolumn{7}{|l|}{ Prematuridade } \\
\hline Faixa um (34 |-| 37 sem) & $163(41,2)$ & $0(0,0)$ & -- & $268(33,5)$ & $4(6,0)$ & $5,60(2,15-14,57)$ \\
\hline Faixa dois $(32 \mid-34 \mathrm{sem})$ & $73(18,4)$ & $0(0,0)$ & -- & $112(14,0)$ & $6(9,0)$ & $1,56(0,71-3,41)$ \\
\hline Faixa três $(28 \mid-32$ sem $)$ & $81(20,4)$ & $5(14,7)$ & $1,39(0,60-3,20)$ & $82(10,2)$ & $32(47,8)$ & $0,21(0,16-0,30)$ \\
\hline Faixa quatro $(<28 \mathrm{sem})$ & $25(6,3)$ & $29(85,3)$ & $0,07(0,04-0,11)$ & $56(7,0)$ & $26(38,8)$ & $0,18(0,12-0,27)$ \\
\hline Corticoindução & $171(43,2)$ & $17(50,0)$ & $0,86(0,61-1,23)$ & $516(64,4)$ & $44(65,7)$ & $0,98(0,82-1,18)$ \\
\hline Monocorionicidade & -- & -- & -- & $288(36,0)$ & $34(50,7)$ & $0,71(0,55-0,91)$ \\
\hline Parto vaginal & $216(54,5)$ & $19(55,9)$ & $0,97(0,71-1,33)$ & $308(38,4)$ & $20(29,8)$ & $1,28(0,88-1,88)$ \\
\hline
\end{tabular}
A análise multivariada (Tabela 7) para o desfecho morbidade composta, considerando gestações únicas, confirmou maior risco deste desfecho apenas em $\mathrm{RN}$ que nasceram em IG <28 semanas. Ao analisar os resultados de gemelares, confirmou-se risco maior de morbidade composta em RN com diagnóstico de SFA, PT com menos de 32 semanas e nos gêmeos MC. Apesar de o parto vaginal ter aumentado o risco de índices de Apgar <7 em gemelares, essa variável não aumentou morbidade composta. Mas, cumpre destacar que os dados devem ser avaliados com certa precaução, uma vez que há intervalos de confianças bastante amplos para algumas variáveis. 
Tabela 7. Efeito das características demográficas maternas e relacionadas à gestação sobre morbidade composta dos recém-nascidos de gestações únicas e gemelares (análise multivariada).

\begin{tabular}{|c|c|c|c|c|c|c|}
\hline \multirow[b]{2}{*}{ VARIÁVEIS } & \multicolumn{3}{|c|}{ Gestação única } & \multicolumn{3}{|c|}{ Gestação gemelar } \\
\hline & OR & IC $95 \%$ & $p$ valor & OR & IC $95 \%$ & $p$ valor \\
\hline Tade ( $\leq 19$ anos $X \geq 35$ anos) & 0,37 & $0,03-3,93$ & 0,29 & 2,07 & $0,59-7,23$ & 0,22 \\
\hline Idade ( $\geq 35$ anos $\times 20-34$ anos) & 0,88 & $0,14-5,45$ & 0,53 & 1,15 & $0,51-2,57$ & 0,52 \\
\hline Cor da pele (branca X não branca) & 1,41 & $0,56-3,52$ & 0,46 & 1,32 & $0,66-2,62$ & 0,43 \\
\hline Estado civil (com X sem companheiro) & 0,95 & $0,33-2,74$ & 0,93 & 1,46 & $0,80-2,66$ & 0,21 \\
\hline Profissão (não X sim) & 0,88 & $0,34-2,29$ & 0,80 & 0,93 & $0,51-1,68$ & 0,81 \\
\hline Tabagismo (não Xsim) & 0,86 & $0,09-8,17$ & 0,89 & 0,74 & $0,35-1,58$ & 0,44 \\
\hline Diabetes mellitus (não X sim) & 0,43 & $0,03-5,11$ & 0,50 & 0,13 & $0,01-5,42$ & 0,28 \\
\hline Hipertensão arterial (não X sim) & 0,37 & $0,06-2,33$ & 0,29 & 0,74 & $0,04-12,83$ & 0,84 \\
\hline Obesidade (não X sim) & 0,95 & $0,20-4,54$ & 0,95 & 0,43 & $0,05-3,31$ & 0,42 \\
\hline Primigravidae (não X sim) & 0,55 & $0,14-2,14$ & 0,39 & 1,23 & $0,65-2,31$ & 0,52 \\
\hline Prematuridade prévia (não X sim) & 1,13 & $0,29-4,44$ & 0,86 & 0,78 & $0,25-2,46$ & 0,68 \\
\hline RCIU (não X sim) & 1,89 & $0,21-17,38$ & 0,57 & 1,11 & $0,49-2,53$ & 0,81 \\
\hline Centralização hemodinâmica (não X sim) & 0,40 & $0,04-4,10$ & 0,44 & 1,47 & $0,51-4,21$ & 0,48 \\
\hline SFA (não X sim) & 2,07 & $0,38-11,11$ & 0,40 & 0,37 & $0,15-0,89$ & 0,03 \\
\hline Oligohidrâmnio (não X sim) & 0,95 & $0,11-8,11$ & 0,96 & 0,69 & $0,17-2,74$ & 0,59 \\
\hline Polihidrâmnio (não X sim) & 0,53 & $0,03-11,02$ & 0,69 & 7,19 & $0,17-16,74$ & 0,22 \\
\hline IG ao nascer $(34-37$ sem $X>37$ sem $)$ & 0,38 & $0,02-6,24$ & 0,50 & 1,13 & $0,34-3,69$ & 0,84 \\
\hline IG ao nascer $(32-34$ sem $X>37$ sem $)$ & 1,08 & $0,06-19,46$ & 0,96 & 1,76 & $0,62-5,04$ & 0,29 \\
\hline IG ao nascer $(28-32$ sem $X>37$ sem $)$ & 7,82 & $0,79-76,60$ & 0,08 & 18,87 & $7,63-46,69$ & $<0,0001$ \\
\hline$I G$ ao nascer $(<28$ sem $X>37$ sem $)$ & 107,74 & $11,19-239,98$ & $<0,0001$ & 32,16 & $11,96-86,47$ & $<0,0001$ \\
\hline Corticoindução (sim X não) & 0,68 & $0,26-1,77$ & 0,007 & 1,45 & $0,74-2,83$ & 0,28 \\
\hline Parto vaginal (sim X não) & 0,59 & $0,21-1,66$ & 0,32 & 0,54 & $0,27-1,05$ & 0,07 \\
\hline Monocorionicidade (DC XMC) & -- & -- & -- & 0,54 & $0,30-0,98$ & 0,04 \\
\hline
\end{tabular}

OR: odds ratio; IC: intervalo de confiança; RCIU: restrição do crescimento intrauterino; SFA: sofrimento fetal agudo; sem: semanas; DC: dicorionicidade; MC: monocorionicidade.

Na Tabela 8 estão demonstradas as influências das variáveis sobre o óbito neonatal das populações estudadas. Semelhante ao que ocorreu na Tabela 6, a análise de algumas variáveis ficou prejudicada pela existência de prevalências nulas. Observando-se as gestações únicas, notou-se que prematuridade abaixo de 28 semanas aumentou o risco de óbito neonatal. Ao contrário, os RN que morreram menos foram os que nasceram após a 34a semana. Com relação às gestações gemelares, houve mais óbito neonatal entre crianças com diagnóstico de RCIU e SFA, da mesma forma que entre as crianças que nasceram com menos de 32 semanas. Similarmente aos RN de gestações únicas, gemelares que nasceram com mais de 34 semanas morreram menos. A Tabela 9 demonstra os resultados da análise multivariada para óbito neonatal. Confirmou-se a IG como fator de risco para esse desfecho entre os RN únicos, com aumento significativo para PT com menos de 34 semanas. Ausência de hipertensão e obesidade materna figurou como fator de proteção para óbito nesse grupo. Para os RN gemelares, ter SFA e nascer antes de 32 semanas foram variáveis que aumentaram o risco de óbito neonatal. 
Tabela 8. Influência das características demográficas maternas e relacionadas à gestação sobre óbito neonatal dos recém-nascidos de gestações únicas e gemelares.

\begin{tabular}{|c|c|c|c|c|c|c|}
\hline \multirow{3}{*}{ Covariáveis } & \multicolumn{3}{|c|}{ Gestação única } & \multicolumn{3}{|c|}{ Gestação gemelar } \\
\hline & Não & Sim & OR (IC95\%) & Não & Sim & OR (IC95\%) \\
\hline & $n(\%)$ & $n(\%)$ & & $n(\%)$ & $n(\%)$ & \\
\hline \multicolumn{7}{|l|}{$\begin{array}{l}\text { Características maternas } \\
\text { Idade }\end{array}$} \\
\hline$\leq 19$ & $45(11,4)$ & $6(16,7)$ & $0,68(0,31-1,49)$ & $63(7,6)$ & $7(15,9)$ & $0,47(0,11-1,39)$ \\
\hline$\overline{1} 9-35$ & $299(75,9)$ & $30(83,3)$ & $0,91(0,78-1,06)$ & $663(80,5)$ & $33(75,0)$ & $1,07(0,68-1,43)$ \\
\hline$\geq 35$ & $50(12,7)$ & $0(0,0)$ & -- & $98(11,9)$ & $4(9,1)$ & $1,31(0,57-2,13)$ \\
\hline \multicolumn{7}{|l|}{ Cor da pele } \\
\hline Branca & $253(64,2)$ & $22(61,1)$ & $1,05(0,80-1,38)$ & $606(73,5)$ & $36(81,8)$ & $0,90(0,78-1,04)$ \\
\hline Não branca & $141(35,8)$ & $14(38,9)$ & $0,92(0,60-1,41)$ & $218(26,5)$ & $8(18,2)$ & $1,46(0,77-2,75)$ \\
\hline \multicolumn{7}{|l|}{ Estado civil } \\
\hline Com companheiro & $255(64,7)$ & $28(77,8)$ & $0,83(0,69-1,01)$ & $420(51,0)$ & $24(54,5)$ & $0,93(0,71-1,23)$ \\
\hline Sem companheiro & $139(35,3)$ & $8(22,2)$ & $1,59(0,85-2,97)$ & $404(49,0)$ & $20(45,4)$ & $1,08(0,77-1,50)$ \\
\hline \multicolumn{7}{|l|}{ Profissão } \\
\hline Não trabalha & $255(64,7)$ & $27(75,0)$ & $0,86(0,71-2,52)$ & $497(60,3)$ & $27(61,4)$ & $0,98(0,77-1,25)$ \\
\hline Trabalha fo & $139(35,3)$ & $9(25,0)$ & $1,41(0,79-2,52)$ & $327(39,7)$ & $17(38,6)$ & $1,03(0,70-1,50)$ \\
\hline Tabagismo & $40(10,2)$ & $2(5,6)$ & $1,83(0,46-7,25)$ & $129(15,7)$ & $5(11,4)$ & $1,38(0,59-3,19)$ \\
\hline Diabetes mellitus & $34(8,6)$ & $0(0,0)$ & -- & $12(1,5)$ & $0(0,0)$ & -- \\
\hline Hipertensão arterial crônica & $94(23,9)$ & $8(22,2)$ & $1,07(0,57-2,03)$ & $56(6,8)$ & $0(0,0)$ & -- \\
\hline Obesidade & $61(15,5)$ & $5(13,9)$ & $1,11(0,48-2,60)$ & $46(5,6)$ & $0(0,0)$ & -- \\
\hline \multicolumn{7}{|l|}{ Dados da gestacão } \\
\hline Primigravidae & $185(46,9)$ & $21(58,3)$ & $0,80(0,59-1,08)$ & $377(45,7)$ & $25(56,8)$ & $0,81(0,62-1,05)$ \\
\hline Antecedente de PPT & $254(64,5)$ & $25(69,4)$ & $0,93(0,74-1,17)$ & $39(4,7)$ & $1(2,3)$ & $2,08(0,29-14,81)$ \\
\hline $\mathrm{RCIU}$ & $48(12,2)$ & $5(13,9)$ & $0,88(0,37-2,06)$ & $84(10,2)$ & $10(22,7)$ & $0,45(0,25-0,80)$ \\
\hline Centralização hemodinâmica & $32(8,1)$ & $4(11,1)$ & $0,73(0,27-1,95)$ & $64(7,8)$ & $6(13,6)$ & $0,57(0,26-1,24)$ \\
\hline SFA & $35(8,9)$ & $3(8,3)$ & $1,07(0,34-3,30)$ & $84(10,2)$ & $10(22,7)$ & $0,45(0,25-0,80)$ \\
\hline Oligohidrâmnio & $25(6,3)$ & $3(8,3)$ & $0,76(0,24-2,40)$ & $25(3,0)$ & $1(2,3)$ & $1,33(0,19-9,63)$ \\
\hline Polihidrâmnio & $8(2,0)$ & $0(0,0)$ & -- & $7(0,8)$ & $1(2,3)$ & $0,37(0,05-2,97)$ \\
\hline \multicolumn{7}{|l|}{ Prematuridade } \\
\hline Faixa um (34 |-| 37 sem) & $162(41,1)$ & $1(2,8)$ & $14,80(2,13-102,61)$ & $265(32,2)$ & $7(15,9)$ & $2,02(1,02-4,02)$ \\
\hline Faixa dois (32|-34 sem) & $70(17,8)$ & $3(8,3)$ & $2,13(0,71-6,43)$ & $115(14,0)$ & $3(6,8)$ & $2,05(0,68-6,18)$ \\
\hline Faixa três $(28 \mid-32 \mathrm{sem})$ & $81(20,6)$ & $5(13,9)$ & $1,48(0,64-3,42)$ & $103(12,5)$ & $11(25,0)$ & $0,50(0,29-0,86)$ \\
\hline atro $(<28 \mathrm{sem})$ & $27(6,8)$ & $27(75,0)$ & $0,09(0,06-0,14)$ & $60(7,3)$ & $22(50,0)$ & $0,15(0,10-0,21)$ \\
\hline Corticoindução & $169(42,9)$ & $19(52,8)$ & $0,81(0,58-1,13)$ & $536(65,1)$ & $24(54,5)$ & $1,19(0,91-1,57)$ \\
\hline Monocorionicidade & -- & -- & -- & $303(36,8)$ & $19(43,2)$ & $0,85(0,60-1,21)$ \\
\hline Parto vaginal & $217(55,1)$ & $18(50,0)$ & $1,10(0,78-1,54)$ & $311(37,7)$ & $17(38,6)$ & $0,97(0,66-1,43)$ \\
\hline
\end{tabular}

OR: odds ratio; PPT: parto pré-termo; RCIU: restrição do crescimento intrauterino; SFA: sofrimento fetal agudo; sem: semanas.

O efeito das variáveis selecionadas sobre o desfecho hipoglicemia neonatal é analisado na Tabela 10. É possível observar que $\mathrm{RN}$ de gestações únicas tiveram menos hipoglicemia quando nasceram com IG >34 semanas e de parto vaginal. Por outro lado, RN que nasceram com <32 semanas apresentaram maior probabilidade de ter hipoglicemia no período neonatal imediato. Ao considerar gestações gemelares, houve prevalências maiores de hipoglicemia nos $\mathrm{RN}$ que eram filhos de mães adolescentes, que tinham características de sofrimento fetal crônico (SFC), ou seja, com RCIU, centralização hemodinâmica e oligohidrâmnio e que nasceram com menos de 34 semanas. É interessante notar que ter recebido corticosteroides 
durante a gestação aumentou a prevalência de RN gemelares com hipoglicemia. Contrariamente, $\mathrm{RN}$ que nasceram de parto vaginal parecem ter menor risco desse desfecho.

Tabela 9. Efeito das características demográficas maternas e relacionadas à gestação sobre óbito neonatal dos recém-nascidos de gestações únicas e gemelares (análise multivariada).

\begin{tabular}{|c|c|c|c|c|c|c|}
\hline \multirow[b]{2}{*}{ VARIÁVEIS } & \multicolumn{3}{|c|}{ Gestação única } & \multicolumn{3}{|c|}{ Gestação gemelar } \\
\hline & OR & IC $95 \%$ & $p$ valor & OR & IC $95 \%$ & $p$ valor \\
\hline Idade ( $\leq 19$ anos $X \geq 35$ anos) & 15,82 & $0,72-343,72$ & 0,10 & 3,42 & $0,83-13,99$ & 0,10 \\
\hline Idade ( $\geq \overline{3} 5$ anos $\times 2 \overline{0}-34$ anos) & 10,25 & $0,68-155,21$ & 0,21 & 1,90 & $0,64-5,64$ & 0,93 \\
\hline Cor da pele (branca X não branca) & 1,22 & $0,51-2,93$ & 0,65 & 1,60 & $0,72-3,55$ & 0,25 \\
\hline Estado civil (com $X$ sem companheiro) & 2,63 & $0,37-2,82$ & 0,07 & 0,94 & $0,49-1,82$ & 0,85 \\
\hline Profissão (não X sim) & 0,92 & $0,34-2,29$ & 0,85 & 0,78 & $0,40-1,52$ & 0,47 \\
\hline Tabagismo (não X sim) & 0,17 & $0,03-1,01$ & 0,05 & 0,74 & $0,35-1,58$ & 0,72 \\
\hline Diabetes mellitus (não X sim) & 1,82 & $0,13-25,24$ & 0,65 & 0,02 & $0,01-1,67$ & 0,08 \\
\hline Hipertensão arterial (não X sim) & 0,14 & $0,02-0,84$ & 0,03 & 0,40 & $0,04-45,02$ & 0,70 \\
\hline Obesidade (não X sim) & 0,11 & $0,02-0,47$ & 0,003 & 0,49 & $0,02-14,86$ & 0,68 \\
\hline Primigravidae (não X sim) & 0,67 & $0,18-2,45$ & 0,54 & 0,77 & $0,38-1,54$ & 0,48 \\
\hline Prematuridade prévia (não X sim) & 1,36 & $0,36-5,08$ & 0,64 & 2,21 & $0,37-13,07$ & 0,38 \\
\hline RCIU (não X sim) & 0,80 & $0,12-5,36$ & 0,81 & 1,17 & $0,44-3,08$ & 0,74 \\
\hline Centralização hemodinâmica (não X sim) & 0,29 & $0,04-1,99$ & 0,21 & 0,81 & $0,26-2,52$ & 0,72 \\
\hline SFA (não X sim) & 1,76 & $0,41-7,63$ & 0,44 & 0,35 & $0,14-0,90$ & 0,03 \\
\hline Oligohidrâmnio (não X sim) & 0,71 & $0,13-3,87$ & 0,69 & 0,85 & $0,14-5,12$ & 0,85 \\
\hline Polihidrâmnio (não X sim) & 0,52 & $0,03-9,82$ & 0,66 & 1,04 & $0,12-8,99$ & 0,96 \\
\hline IG ao nascer (34-37 sem $X>37$ sem $)$ & 2,43 & $0,14-4,09$ & 0,53 & 2,43 & $0,73-8,11$ & 0,14 \\
\hline IG ao nascer $(32-34$ sem $X>37$ sem $)$ & 19,35 & $1,09-34,04$ & 0,04 & 1,59 & $0,44-5,69$ & 0,47 \\
\hline IG ao nascer $(28-32$ sem $X>37$ sem $)$ & 15,36 & $1,04-27,95$ & 0,05 & 10,13 & $3,29-31,19$ & $<0,0001$ \\
\hline IG ao nascer (<28 sem $X>37$ sem $)$ & 297,57 & $18,05-419,97$ & $<0,0001$ & 38,35 & $12,21-120,39$ & $<0,0001$ \\
\hline Corticoindução (sim Xnão) & 0,51 & $0,20-1,35$ & 0,17 & 1,07 & $0,51-2,23$ & 0,85 \\
\hline Parto vaginal (sim Xnão) & 0,41 & $0,15-1,16$ & 0,09 & 0,68 & $0,31-1,46$ & 0,32 \\
\hline Monocorionicidade (DC XMC) & -- & -- & -- & 0,98 & $0,51-1,91$ & 0,97 \\
\hline
\end{tabular}

OR: odds ratio; IC: intervalo de confiança; RClU: restrição do crescimento intrauterino; SFA: sofrimento fetal agudo; sem: semanas; DC: dicorionicidade; MC: monocorionicidade.

Após análise multivariada (Tabela 11), pôde-se confirmar o maior risco de hipoglicemia em crianças de gestações únicas que nasceram com menos de 32 semanas. Nascer de parto vaginal protegeu os RN únicos da hipoglicemia. Outro dado que merece destaque, que não havia sido evidenciado na Tabela 10, é o caráter protetor que a ausência de Diabetes materna confere aos RN únicos em relação à hipoglicemia. Com relação aos gemelares, confirmou-se o maior risco de hipoglicemia neonatal naqueles filhos de mães adolescentes, que apresentaram oligohidrâmnio e nos PT com menos de 34 semanas. Nessa população, o parto vaginal também teve um efeito protetor. O efeito do corticóide sobre esse desfecho foi afastado após análise multivariada. 
Tabela 10. Influência das características demográficas maternas e relacionadas à gestação sobre a ocorrência de hipoglicemia dos recém-nascidos de gestações únicas e gemelares.

\begin{tabular}{|c|c|c|c|c|c|c|}
\hline \multirow{3}{*}{ Covariáveis } & \multicolumn{3}{|c|}{ Gestação única } & \multicolumn{3}{|c|}{ Gestação gemelar } \\
\hline & Não & Sim & OR (IC95\%) & Não & Sim & OR (IC95\%) \\
\hline & $n(\%)$ & $n(\%)$ & & $n(\%)$ & $n(\%)$ & \\
\hline \multicolumn{7}{|l|}{$\begin{array}{l}\text { Características maternas } \\
\text { Idade }\end{array}$} \\
\hline$\leq 19$ & $41(11,2)$ & $10(15,4)$ & $0,73(0,39-1,38)$ & $57(7,2)$ & $13(16,9)$ & $0,43(0,24-0,74)$ \\
\hline $19-35$ & $280(76,7)$ & $49(75,4)$ & $1,01(0,88-1,18)$ & $639(80,8)$ & $57(74,0)$ & $1,09(0,95-1,25)$ \\
\hline$\geq 35$ & $44(12,0)$ & $6(9,2)$ & $1,30(0,58-2,93)$ & $95(12,0)$ & $7(9,1)$ & $1,32(0,63-2,74)$ \\
\hline \multicolumn{7}{|l|}{ Cor da pele } \\
\hline Branca & $238(65,2)$ & $37(56,9)$ & $1,15(0,92-1,43)$ & $582(73,6)$ & $60(77,9)$ & $0,94(0,83-1,07)$ \\
\hline Não branca & $127(35,6)$ & $28(43,1)$ & $0,81(0,60-1,10)$ & $209(26,4)$ & $17(22,1)$ & $1,20(0,77-1,85)$ \\
\hline \multicolumn{7}{|l|}{ Estado civil } \\
\hline Com companheiro & $237(64,9)$ & $46(70,8)$ & $0,92(0,77-1,09)$ & $408(51,6)$ & $36(46,7)$ & $1,10(0,86-1,41)$ \\
\hline Sem companheiro & $128(35,1)$ & $19(29,2)$ & $1,19(0,80-1,79)$ & $383(48,4)$ & $41(53,3)$ & $0,91(0,73-1,13)$ \\
\hline \multicolumn{7}{|l|}{ Profissão } \\
\hline Não trabalha & $235(64,4)$ & $47(72,3)$ & $0,89(0,75-1,95)$ & $476(60,2)$ & $48(62,3)$ & $0,97(0,80-1,16)$ \\
\hline Trabalha fora & $130(35,6)$ & $18(27,7)$ & $1,29(0,84-1,95)$ & $315(39,8)$ & $29(37,7)$ & $1,05(0,78-1,43)$ \\
\hline Tabagismo & $34(9,3)$ & $8(12,3)$ & $0,76(0,37-1,56)$ & $120(15,2)$ & $14(18,2)$ & $0,83(0,51-1,38)$ \\
\hline Diabetes mellitus & $27(7,4)$ & $7(10,8)$ & $0,69(0,31-1,51)$ & $11(1,4)$ & $1(1,3)$ & $1,07(0,14-8,18)$ \\
\hline Hipertensão arterial crônica & $88(24,1)$ & $14(21,5)$ & $1,12(0,68-1,84)$ & $53(5,2)$ & $3(6,5)$ & $0,97(0,92-5,37)$ \\
\hline Obesidade & $59(16,2)$ & $7(10,8)$ & $1,50(0,72-3,14)$ & $41(5,6)$ & $5(6,5)$ & $0,80(0,32-1,96)$ \\
\hline \multicolumn{7}{|l|}{ Dados da gestacão } \\
\hline Primigravidae & $172(47,1)$ & $34(52,3)$ & $0,91(0,69-1,16)$ & $370(46,8)$ & $32(41,6)$ & $1,13(0,85-1,48)$ \\
\hline Antecedente de PPT & $236(64,7)$ & $43(66,1)$ & $0,98(0,81-1,18)$ & $38(4,8)$ & $2(2,6)$ & $1,85(0,45-7,52)$ \\
\hline RCIU & $42(11,5)$ & $11(16,9)$ & $0,68(0,37-1,25)$ & $79(10,0)$ & $15(19,5)$ & $0,51(0,31-0,85)$ \\
\hline Centralização hemodinâmica & $29(8,0)$ & $7(10,8)$ & $0,74(0,34-1,61)$ & $59(7,5)$ & $11(14,3)$ & $0,52(0,29-0,95)$ \\
\hline SFA & $31(8,5)$ & $7(10,8)$ & $0,79(0,36-1,71)$ & $81(10,2)$ & $13(16,9)$ & $0,61(0,35-1,04)$ \\
\hline Oligohidrâmnio & $24(6,6)$ & $4(6,1)$ & $1,07(0,38-2,98)$ & $20(2,5)$ & $6(7,8)$ & $0,32(0,13-0,78)$ \\
\hline Polihidrâmnio & $7(1,9)$ & $1(1,5)$ & $1,24(0,16-9,96)$ & $8(1,0)$ & $0(0,0)$ & -- \\
\hline \multicolumn{7}{|l|}{ Prematuridade } \\
\hline Faixa um (34 |-| 37 sem $)$ & $150(41,1)$ & $13(20,0)$ & $2,05(1,24-3,39)$ & $252(31,9)$ & $20(26,0)$ & $1,22(0,83-1,81)$ \\
\hline Faixa dois (32|-34 sem) & $65(17,8)$ & $8(12,3)$ & $1,45(0,73-2,87)$ & $96(12,1)$ & $22(28,6)$ & $0,42(0,28-0,63)$ \\
\hline Faixa três (28 |- 32 sem) & $66(18,1)$ & $20(30,8)$ & $0,59(0,38-0,90)$ & $97(12,3)$ & $17(22,1)$ & $0,55(0,36-0,88)$ \\
\hline Faixa quatro (<28 sem) & $32(8,8)$ & $22(33,8)$ & $0,26(0,16-0,42)$ & $74(9,4)$ & $8(10,4)$ & $0,90(0,45-1,80)$ \\
\hline Corticoindução & $157(43,0)$ & $31(47,7)$ & $0,90(0,68-1,19)$ & $501(63,3)$ & $59(76,6)$ & $0,83(0,72-0,94)$ \\
\hline Monocorionicidade & -- & -- & -- & $287(36,3)$ & $35(45,4)$ & $0,80(0,61-1,04)$ \\
\hline Parto vaginal & $209(57,3)$ & $26(40,0)$ & $1,43(1,05-1,95)$ & $311(39,3)$ & $17(22,1)$ & $1,78(1,16-2,73)$ \\
\hline
\end{tabular}

$\mathrm{Na}$ Tabela 12, vemos como as variáveis interferiram no desfecho icterícia neonatal. Na população de gestações únicas, observamos que RN de mães com companheiro têm probabilidade maior de terem icterícia, assim como filhos de mães com antecedente de diabetes mellitus e hipertensão arterial à gestação. Ainda, RN que tiveram o diagnóstico de centralização hemodinâmica e de SFA na gestação também apresentaram icterícia mais frequentemente, da mesma forma que aqueles que nasceram antes da $32^{\mathrm{a}}$ semana. O parto vaginal parece proteger esses $\mathrm{RN}$ deste resultado. $\mathrm{Na}$ análise das gestações gemelares, RN de mães sem companheiro têm probabilidade maior de terem icterícia, da mesma maneira que crianças que nasceram entre 28 e 34 semanas. A corticoindução e a 
monocorionicidade parecem aumentar a probabilidade de icterícia nos $\mathrm{RN}$ de gestação múltipla. Nesse grupo, o parto vaginal também parece proteger os RN deste desfecho.

Tabela 11. Efeito das características demográficas maternas e relacionadas à gestação sobre hipoglicemia neonatal dos recém-nascidos de gestações únicas e gemelares (análise multivariada).

\begin{tabular}{|c|c|c|c|c|c|c|}
\hline \multirow[b]{2}{*}{ VARIAVEEIS } & \multicolumn{3}{|c|}{ Gestação única } & \multicolumn{3}{|c|}{ Gestação gemelar } \\
\hline & OR & IC $95 \%$ & $p$ valor & OR & IC $95 \%$ & $p$ valor \\
\hline Idade ( $\leq 19$ anos X20 - 34 anos) & 1,14 & $0,32-4,02$ & 0,81 & 4,44 & $1,51-13,04$ & 0,001 \\
\hline Idade ( $\geq 35$ anos $\times 20-34$ anos $)$ & 1,04 & $0,40-2,68$ & 0,92 & 1,22 & $0,54-2,74$ & 0,07 \\
\hline Cor da pele (branca Xnão branca) & 0,91 & $0,51-1,63$ & 0,76 & 1,15 & $0,64-2,08$ & 0,63 \\
\hline Estado civil (com Xsem companheiro) & 1,13 & $0,60-2,13$ & 0,69 & 0,82 & $0,50-1,33$ & 0,43 \\
\hline Profissão (não $X$ sim) & 1,30 & $0,70-2,40$ & 0,40 & 1,14 & $0,69-1,89$ & 0,59 \\
\hline Tabagismo (não Xsim) & 0,38 & $0,13-1,11$ & 0,08 & 0,91 & $0,48-1,71$ & 0,76 \\
\hline Diabetes mellitus (não X sim) & 0,22 & $0,07-0,67$ & 0,007 & 4,28 & $0,16-110,62$ & 0,38 \\
\hline Hipertensão arterial (não X sim) & 0,68 & $0,25-1,81$ & 0,44 & 0,21 & $0,11-3,93$ & 0,54 \\
\hline Obesidade (não X sim) & 1,38 & $0,52-3,66$ & 0,51 & 4,18 & $0,24-14,86$ & 0,33 \\
\hline Primigravidae (não Xsim) & 0,72 & $0,31-1,68$ & 0,45 & 1,51 & $0,87-2,60$ & 0,14 \\
\hline Prematuridade prévia (não X sim) & 1,11 & $0,47-2,59$ & 0,81 & 1,79 & $0,47-6,81$ & 0,39 \\
\hline RCIU (não Xsim) & 0,36 & $0,11-1,15$ & 0,08 & 0,75 & $0,34-1,65$ & 0,48 \\
\hline Centralização hemodinâmica (não X sim) & 1,64 & $0,42-6,38$ & 0,47 & 0,96 & $0,40-2,33$ & 0,93 \\
\hline SFA (não X sim) & 0,95 & $0,34-2,64$ & 0,91 & 0,90 & $0,41-2,00$ & 0,80 \\
\hline Oligohidrâmnio (não X sim) & 1,24 & $0,33-4,68$ & 0,74 & 0,28 & $0,10-0,82$ & 0,02 \\
\hline Polihidrâmnio (não X sim) & 0,75 & $0,10-5,50$ & 0,78 & 4,13 & 0,19-87,99 & 0,36 \\
\hline IG ao nascer (34-37 sem $X>37$ sem $)$ & 2,09 & $0,53-8,25$ & 0,29 & 1,56 & $0,79-3,08$ & 0,19 \\
\hline IG ao nascer $(32-34$ sem $X>37$ sem $)$ & 3,44 & $0,76-15,59$ & 0,10 & 3,40 & $1,71-6,73$ & 0,0004 \\
\hline IG ao nascer $(28-32$ sem $X>37$ sem $)$ & 8,54 & $2,07-35,27$ & 0,003 & 2,80 & $1,37-5,74$ & 0,005 \\
\hline IG ao nascer (<28 sem $X>37$ sem $)$ & 20,44 & $4,89-85,45$ & $<0,0001$ & 2,39 & $1,04-5,81$ & 0,04 \\
\hline Corticoindução (sim X não) & 0,65 & $0,35-1,24$ & 0,19 & 1,77 & $0,99-3,15$ & 0,05 \\
\hline Parto vaginal (sim Xnão) & 0,35 & $0,18-0,68$ & 0,002 & 0,43 & $0,24-0,78$ & 0,005 \\
\hline Monocorionicidade (DC XMC) & -- & -- & -- & 0,79 & $0,48-1,29$ & 0,34 \\
\hline
\end{tabular}

OR: odds ratio; IC: intervalo de confiança; RCIU: restrição do crescimento intrauterino; SFA: sof rimento fetal agudo; sem: semanas; DC: dicorionicidade; MC: monocorionicidade.

A Tabela 13 demonstra a análise multivariada para o desfecho icterícia neonatal. Hipertensão e Diabetes materna e prematuridade abaixo de 32 semanas foram variáveis confirmadas como fatores de risco para esse desfecho entre os $\mathrm{RN}$ de gestações únicas. Considerando os gemelares, como sugerido pela Tabela 12, foram confirmados os seguintes fatores de risco para icterícia neonatal: mães sem companheiro, prematuridade inferior à $37^{\text {a }}$ semana, corticoindução e monocorionicidade. Não ter RClU protegeu significativamente o RN da gestação múltipla de ter esse resultado adverso. Em ambas as populações, o parto vaginal foi afastado como fator protetor. 
Tabela 12. Influência das características demográficas maternas e relacionadas à gestação sobre a ocorrência de icterícia dos recém-nascidos de gestações únicas e gemelares.

\begin{tabular}{|c|c|c|c|c|c|c|}
\hline \multirow{3}{*}{ Covariáveis } & \multicolumn{3}{|c|}{ Gestação única } & \multicolumn{3}{|c|}{ Gestação gemelar } \\
\hline & Não & Sim & OR (IC95\%) & Não & Sim & OR (IC95\%) \\
\hline & $n(\%)$ & $\mathrm{n}(\%)$ & & $n(\%)$ & $\mathrm{n}(\%)$ & \\
\hline \multicolumn{7}{|l|}{$\begin{array}{l}\text { Características maternas } \\
\text { ldade }\end{array}$} \\
\hline$\leq 19$ & $39(11,8)$ & $12(12,0)$ & $0,98(0,54-1,80)$ & $48(8,5)$ & $22(7,3)$ & $1,17(0,72-1,90)$ \\
\hline $19-35$ & $255(77,3)$ & $74(74,0)$ & $1,04(0,92-1,18)$ & $451(79,8)$ & $245(80,9)$ & $0,99(0,92-1,05)$ \\
\hline$\geq 35$ & $36(10,9)$ & $14(14,4)$ & $0,77(0,44-1,38)$ & $66(11,7)$ & $36(11,9)$ & $0,98(0,67-1,44)$ \\
\hline \multicolumn{7}{|l|}{ Còr da pele } \\
\hline Branca & $217(65,8)$ & $58(58,0)$ & $1,13(0,94-1,36)$ & $412(72,9)$ & $230(75,9)$ & $0,96(0,89-1,04)$ \\
\hline Não branca & $113(34,2)$ & $42(42,0)$ & $0,81(0,62-1,07)$ & $153(27,1)$ & $73(24,1)$ & $1,12(0,88-1,44)$ \\
\hline \multicolumn{7}{|l|}{ Estado civil } \\
\hline Com companheiro & $206(62,4)$ & $77(77,0)$ & $0,81(0,71-0,93)$ & $310(54,9)$ & $134(44,2)$ & $1,24(1,07-1,43)$ \\
\hline Sem companheiro & $124(37,6)$ & $23(23,0)$ & $1,63(1,11-2,40)$ & $255(45,1)$ & $169(55,8)$ & $0,81(0,71-0,93)$ \\
\hline \multicolumn{7}{|l|}{ Profissão } \\
\hline Não trabalha & $213(64,5)$ & $69(69,0)$ & $0,94(0,80-1,09)$ & $333(58,9)$ & $191(63,0)$ & $0,93(084-1,04)$ \\
\hline Trabalha fora & $117(35,4)$ & $31(31,0)$ & $1,14(0,83-1,59)$ & $232(41,1)$ & $112(37,0)$ & $1,11(0,93-1,33)$ \\
\hline Tabagismo & $36(10,9)$ & $6(6,0)$ & $1,81(0,79-4,19)$ & $84(14,9)$ & $50(16,5)$ & $0,90(0,65-1,24)$ \\
\hline Diabetes mellitus & $15(4,5)$ & $19(19,0)$ & $0,24(0,13-0,45)$ & $8(1,4)$ & $4(1,3)$ & $1,07(0,33-3,53)$ \\
\hline Hipertensão arterial crônica & $70(21,2)$ & $32(32,0)$ & $0,66(0,47-0,94)$ & $35(6,2)$ & $21(6,9)$ & $0,89(0,53-1,51)$ \\
\hline $\begin{array}{l}\text { Obesidade } \\
\text { Dados da gestação }\end{array}$ & $46(13,9)$ & $20(20,0)$ & $0,70(0,43-1,12)$ & $24(4,2)$ & $22(7,3)$ & $1,03(0,99-1,07)$ \\
\hline Primigravidae & $163(49,4)$ & $43(43,0)$ & $1,15(0,89-1,48)$ & $272(48,1)$ & $130(42,9)$ & $1,12(0,96-1,31)$ \\
\hline Antecedente de PPT & $218(66,1)$ & $61(61,0)$ & $1,08(0,91-1,29)$ & $27(4,8)$ & $13(4,3)$ & $1,11(0,58-2,13)$ \\
\hline RCIU & $39(11,8)$ & $14(14,0)$ & $0,84(0,48-1,49)$ & $64(11,3)$ & $30(9,9)$ & $1,14(0,76-1,72)$ \\
\hline Centralização hemodinâmica & $22(6,7)$ & $14(14,0)$ & $0,48(0,25-0,90)$ & $39(6,9)$ & $31(10,2)$ & $0,67(0,43-1,06)$ \\
\hline SFA & $24(7,3)$ & $14(14,0)$ & $0,52(0,28-0,96)$ & $56(9,9)$ & $38(12,5)$ & $0,79(0,54-1,16)$ \\
\hline Oligohidrâmnio & $20(6,1)$ & $8(8,0)$ & $0,76(0,34-1,66)$ & $19(3,4)$ & $7(2,3)$ & $1,46(0,62-3,42)$ \\
\hline Polihidrâmnio & $6(1,8)$ & $2(2,0)$ & $0,90(0,19-4,43)$ & $5(0,9)$ & $3(1,0)$ & $0,89(0,21-3,71)$ \\
\hline \multicolumn{7}{|l|}{ Prematuridade } \\
\hline Faixa um (34 |-| 37 sem) & $140(42,4)$ & $23(23,0)$ & $1,84(1,26-2,70)$ & $171(30,3)$ & $101(33,3)$ & $0,91(0,74-1,11)$ \\
\hline Faixa dois (32|-34 sem) & $60(18,2)$ & $13(13,0)$ & $1,40(0,80-2,44)$ & $48(8,5)$ & $70(23,1)$ & $0,37(0,26-0,52)$ \\
\hline Faixa três (28|-32 sem) & $53(16,1)$ & $33(33,0)$ & $0,49(0,33-0,71)$ & $56(9,9)$ & $58(19,1)$ & $0,52(0,37-0,72)$ \\
\hline Faixa quatro (<28 sem) & $27(8,2)$ & $27(27,0)$ & $0,30(0,19-0,49)$ & $60(10,2)$ & $22(7,3)$ & $1,46(0,91-2,34)$ \\
\hline Corticoindução & $137(41,5)$ & $51(51,0)$ & $0,81(0,64-1,02)$ & $333(58,9)$ & $227(74,9)$ & $0,79(0,71-0,86)$ \\
\hline Monocorionicidade & -- & -- & -- & $192(34,0)$ & $130(42,9)$ & $0,79(0,67-0,94)$ \\
\hline Parto vaginal & $190(57,6)$ & $45(45,0)$ & $1,28(1,01-1,62)$ & $228(40,3)$ & $100(33,0)$ & $1,22(1,01-1,47)$ \\
\hline
\end{tabular}

A Tabela 14 representa o efeito das variáveis selecionadas sobre óbito fetal nas populações estudadas. Apesar da quantidade significativa de prevalências nulas, a importância do desfecho merece que alguns resultados sejam comentados. A análise multivariada ficou bastante prejudicada, por isso deve ser vista com cautela. Nas gestações únicas, não ter companheiro parece aumentar a probabilidade de feto morto, porém esse achado não foi confirmado na análise multivariada (OR: 0,34; IC95\% 0,08-1,48). Também é possível observar elevada prevalência de óbitos em gestações com menos de 28 semanas, podendo estar esse fato relacionado com algumas condições patológicas fetais mais graves que promovem a morte em IG precoces. Esse dado também foi confirmado na análise 
multivariada (OR:75,78; IC95\% 2,92-253,47). Além disso, torna-se interessante destacar as prevalências nulas de óbito fetal entre mães que fumavam e nos grupos de fetos com RCIU e centralização hemodinâmica, nos atrevendo a sugerir o papel positivo da monitorização fetal mais amiúde. A casuística insuficiente de fetos mortos não permitiu reproduzir esses achados na análise multivariada.

Tabela 13. Efeito das características demográficas maternas e relacionadas à gestação sobre icterícia neonatal dos recém-nascidos de gestações únicase gemelares (análise multivariada).

\begin{tabular}{|c|c|c|c|c|c|c|}
\hline & \multicolumn{3}{|c|}{ Gestação única } & \multicolumn{3}{|c|}{ Gestação gemelar } \\
\hline VARIÁVEIS & OR & IC 95\% & $p$ valor & OR & IC 95\% & $p$ valor \\
\hline Idade ( $\leq 19$ anos $X \geq 35$ anos) & 1,07 & $0,34-3,38$ & 0,72 & 0,79 & $0,38-1,67$ & 0,55 \\
\hline Idade $(20-34$ anos $\bar{X} \geq 35$ anos $)$ & 0,81 & $0,35-1,85$ & 0,43 & 0,93 & $0,54-1,50$ & 0,84 \\
\hline Cor da pele (branca $X$ não branca) & 0,65 & $0,38-1,12$ & 0,12 & 0,91 & $0,64-1,30$ & 0,62 \\
\hline Estado civil (com $X$ sem companheiro) & 1,77 & $0,98-3,21$ & 0,64 & 0,82 & $0,47-0,87$ & 0,004 \\
\hline Profissão (não X sim) & 1,16 & $0,66-2,04$ & 0,59 & 1,19 & $0,85-1,63$ & 0,29 \\
\hline Tabagismo (não Xsim) & 1,01 & $0,32-3,17$ & 0,98 & 0,95 & $0,63-1,45$ & 0,83 \\
\hline Diabetes mellitus (não X sim) & 0,07 & $0,02-0,20$ & $<0,0001$ & 2,56 & $0,47-13,93$ & 0,28 \\
\hline Hipertensão arterial (não X sim) & 0,33 & $0,13-0,86$ & 0,02 & 2,80 & $0,67-11,79$ & 0,16 \\
\hline Obesidade (não Xsim) & 0,62 & $0,27-1,43$ & 0,26 & 0,78 & $0,21-2,87$ & 0,71 \\
\hline Primigravidae (não X sim) & 1,73 & $0,82-3,68$ & 0,15 & 1,13 & $0,81-1,57$ & 0,46 \\
\hline Prematuridade prévia (não X'sim) & 0,83 & $0,39-1,78$ & 0,63 & 1,48 & $0,70-3,11$ & 0,30 \\
\hline RCIU (não X sim) & 2,22 & $0,62-7,96$ & 0,22 & 0,38 & $0,27-0,45$ & 0,007 \\
\hline Centralização hemodinâmica (não X sim) & 0,33 & $0,09-1,27$ & 0,10 & 0,71 & $0,37-1,36$ & 0,30 \\
\hline SFA (não X sim) & 0,80 & $0,31-2,03$ & 0,63 & 0,97 & $0,55-1,71$ & 0,92 \\
\hline Oligohidrâmnio (não X sim) & 0,54 & $0,16-1,87$ & 0,33 & 0,91 & $0,35-2,36$ & 0,85 \\
\hline Polihidrâmnio (não Xsim) & 0,72 & $0,12-4,24$ & 0,71 & 0,65 & $0,13-3,12$ & 0,59 \\
\hline IG ao nascer (34-37 sem $X>37$ sem $)$ & 2,23 & $0,70-7,12$ & 0,17 & 2,31 & $1,56-3,40$ & $<0,0001$ \\
\hline IG ao nascer (32-34 sem $X>37$ sem $)$ & 2,78 & $0,74-10,49$ & 0,13 & 5,01 & $3,08-8,13$ & $<0,0001$ \\
\hline IG ao nascer $(28-32$ sem $X>37$ sem $)$ & 11,23 & $3,29-38,25$ & 0,0001 & 4,03 & $2,44-6,67$ & $<0,0001$ \\
\hline IG ao nascer (<28 sem $X>37$ sem $)$ & 20,73 & $5,94-72,28$ & $<0,0001$ & 1,93 & $1,06-3,51$ & 0,03 \\
\hline Corticoindução (sim Xnão) & 0,76 & $0,42-1,39$ & 0,37 & 1,81 & $1,29-2,55$ & 0,006 \\
\hline Parto vaginal (sim X não) & 0,61 & $0,33-1,13$ & 0,12 & 0,87 & $0,62-1,21$ & 0,41 \\
\hline Monocorionicidade (DC XMC) & -- & -- & & 0,67 & $0,49-0,92$ & 0,01 \\
\hline
\end{tabular}

OR: odds ratio; IC: intervalo de confiança; RCIU: restrição do crescimento intrauterino; SFA: sof rimento fetal agudo; sem: semanas; DC: dicorionicidade; MC: monocorionicidade.

Entre as gestações gemelares, RCIU e polihidrâmnio foram duas variáveis que sugeriram maior probabilidade de morte fetal, porém esses dados não foram confirmados na análise multivariada (OR: 0,31; IC95\% 0,14-0,72; OR: 0,18; IC95\% 0,03-1,17). Assim como nos fetos únicos, houve mais óbito fetal em IG <28 semanas e, nesse grupo, as complicações da monocorionicidade como condições graves poderiam ser aventadas como causas, porém a análise multivariada não demonstrou esta variável como fator de risco (DC X MC, OR: 0,67; IC95\% 0,381,16). Cumpre destacar a influência positiva da corticoindução sobre esse desfecho, também observado na multivariada (OR: 0,34; IC95\% 0,19-0,62). Dados interessantes adicionais são as prevalências nulas de morte fetal entre gestantes 
neste grupo. Mais uma vez, monitorização mais intensa dos fetos pode ser responsável por esses resultados e a casuística insuficiente não permitiu confirmação desse achado na análise multivariada.

Tabela 14. Influência das características demográficas maternas e relacionadas à gestação sobre a ocorrência de óbito fetal em gestações únicas e gemelares.

\begin{tabular}{|c|c|c|c|c|c|c|}
\hline \multirow{3}{*}{ Covariáveis } & \multicolumn{3}{|c|}{ Gestação única } & \multicolumn{3}{|c|}{ Gestação gemelar } \\
\hline & Não & Sim & OR (IC95\%) & Não & Sim & OR (IC95\%) \\
\hline & $n(\%)$ & $\mathrm{n}(\%)$ & & $n(\%)$ & $n(\%)$ & \\
\hline \multicolumn{7}{|l|}{$\begin{array}{l}\text { Características maternas } \\
\text { ldade }\end{array}$} \\
\hline$\leq 19$ & $49(11,6)$ & $2(25,0)$ & $0,46(0,14-1,59)$ & $62(7,7)$ & $8(12,1)$ & $0,64(0,21-1,97)$ \\
\hline $19-35$ & $323(76,5)$ & $6(75,0)$ & $1,02(0,68-1,53)$ & $646(80,5)$ & $50(75,8)$ & $1,06(0,58-1,93)$ \\
\hline$\geq 35$ & $50(11,8)$ & $0(0,0)$ & -- & $94(11,7)$ & $8(12,1)$ & $0,97(0,81-1,13)$ \\
\hline \multicolumn{7}{|l|}{ Cor da pele } \\
\hline Branca & $270(64,0)$ & $5(62,5)$ & $1,02(0,60-1,76)$ & $592(73,8)$ & $50(75,8)$ & $0,97(0,84-1,12)$ \\
\hline Não branca & $152(36,0)$ & $3(37,5)$ & $0,96(0,39-2,37)$ & $210(26,2)$ & $16(24,2)$ & $1,08(0,69-1,68)$ \\
\hline \multicolumn{7}{|l|}{ Estado civil } \\
\hline Com companheiro & $280(66,3)$ & $3(37,5)$ & $1,76(0,72-4,34)$ & $412(51,4)$ & $32(48,5)$ & $1,06(0,81-1,37)$ \\
\hline Sem companheiro & $142(33,6)$ & $5(62,5)$ & $0,54(0,31-0,93)$ & $390(48,6)$ & $34(51,5)$ & $0,94(0,73-1,20)$ \\
\hline \multicolumn{7}{|l|}{ Profissão } \\
\hline Não trabalha & $275(65,2)$ & $7(87,5)$ & $0,74(0,57-1,00)$ & $486(60,6)$ & $38(57,6)$ & $1,05(0,85-1,30)$ \\
\hline Trabalha fora & $147(34,8)$ & $1(12,5)$ & $2,79(0,44-17,51)$ & $316(39,4)$ & $28(42,4)$ & $0,93(0,69-1,24)$ \\
\hline Tabagismo & $42(10,0)$ & $0(0,0)$ & -- & $124(15,5)$ & $10(15,1)$ & $1,02(0,56-1,85)$ \\
\hline Diabetes mellitus & $33(7,8)$ & $1(12,5)$ & $0,63(0,10-4,03)$ & $10(1,3)$ & $2(3,0)$ & $0,41(0,09-1,84)$ \\
\hline Hipertensão arterial crônica & $99(23,5)$ & $3(37,5)$ & $0,63(0,25-1,56)$ & $56(7,0)$ & $0(0,0)$ & -- \\
\hline Obesidade & $65(15,4)$ & $1(12,5)$ & $1,23(0,19-7,81)$ & $46(5,7)$ & $0(0,0)$ & -- \\
\hline \multicolumn{7}{|l|}{ Dados da gestação } \\
\hline Primigravidae & $202(47,9)$ & $4(50,0)$ & $0,96(0,47-1,93)$ & $370(46,1)$ & $32(48,5)$ & $0,95(0,73-1,23)$ \\
\hline Antecedente de PPT & $275(65,2)$ & $4(50,0)$ & $1,30(0,65-2,61)$ & $38(4,7)$ & $2(3,0)$ & $1,56(0,39-6,33)$ \\
\hline RCIU & $53(12,6)$ & $0(0,0)$ & -- & $74(9,2)$ & $20(30,3)$ & $0,30(0,19-0,47)$ \\
\hline Centralização hemodinâmica & $36(8,5)$ & $0(0,0)$ & -- & $66(8,2)$ & $4(6,1)$ & $1,35(0,51-3,61)$ \\
\hline SFA & $36(8,5)$ & $2(25,0)$ & $0,34(0,10-1,18)$ & $84(10,5)$ & $10(15,5)$ & $0,69(0,38-1,27)$ \\
\hline Oligohidrâmnio & $28(6,6)$ & $0(0,0)$ & -- & $23(2,9)$ & $3(4,5)$ & $0,63(0,19-2,05)$ \\
\hline Polihidrâmnio & $8(1,9)$ & $0(0,0)$ & -- & $4(0,5)$ & $4(6,1)$ & $0,08(0,02-0,32)$ \\
\hline \multicolumn{7}{|l|}{ Prematuridade } \\
\hline Faixa um (34 |-| 37 sem $)$ & $163(38,6)$ & $0(0,0)$ & -- & $262(32,7)$ & $10(15,1)$ & $2,15(1,20-3,84)$ \\
\hline Faixa dois (32|-34 sem) & $72(17,1)$ & $1(12,5)$ & $1,36(0,22-8,64)$ & $110(13,7)$ & $8(12,1)$ & $1,13(0,58-2,21)$ \\
\hline Faixa três $(28 \mid-32$ sem $)$ & $85(20,1)$ & $1(12,5)$ & $1,61(0,26-10,18)$ & $106(13,2)$ & $8(12,1)$ & $1,09(0,55-2,14)$ \\
\hline Faixa quatro $(<28 \mathrm{sem})$ & $48(11,4)$ & $6(75,0)$ & $0,15(0,09-0,24)$ & $54(6,7)$ & $28(42,2)$ & $0,16(0,10-0,23)$ \\
\hline Corticoindução & $186(44,1)$ & $2(25,0)$ & $1,76(0,52-5,88)$ & $538(67,1)$ & $22(33,3)$ & $2,01(1,42-2,84)$ \\
\hline Monocorionicidade & -- & -- & -- & $286(35,7)$ & $36(54,5)$ & $0,65(0,51-0,83)$ \\
\hline
\end{tabular}


7. DISCUSSÃO 
As gestações múltiplas apresentaram incidência e prevalência aumentadas nos últimos anos, o que justifica a existência de serviços acadêmicos com nível de complexidade terciário e com protocolos voltados para assistência das mesmas e suas potenciais complicações, como este onde se deu a realização do presente estudo. A gemelaridade impõe maior sobrecarga e consequente adaptação exacerbada do organismo materno frente às necessidades de mais de um produto conceptual. Tal demanda aumentada, em associação com certas condições e doenças maternas pré-existentes, elevam o risco das gestantes portadoras de gemelares apresentarem maior morbimortalidade e cifras elevadas de resultados perinatais adversos. Não foi ocasional demonstrarmos neste estudo que a ausência de doenças maternas e de condições de risco, como a obesidade ou tabagismo, protegeram os RN de resultados adversos, tanto nas gestações únicas como nas gemelares.

O presente estudo mostrou que as gestações gemelares estão realmente associadas a maiores taxas de intercorrências maternas e perinatais. Embora as gestantes com fetos únicos, quando comparadas às gestações gemelares, apresentassem prevalências maiores de doenças, como Diabetes, hipertensão e obesidade, as incidências de óbito fetal, baixo peso ao nascer, necessidade de analgesia de parto, cesárea e complicações puerperais, como hemorragia e infecção, foram maiores nas gestações múltiplas. Esses dados são corroborados por vários autores que avaliaram resultados maternos e perinatais (Hack et al., 2008; NICE, 2011; Doss et al., 2012; ACOG, 2014; Santana et al., 2016). Alguns resultados adversos neonatais foram significativamente mais frequentes nas gestações gemelares MC. Considerando ambas as populações, as prevalências de gestações DC e MC na nossa população $(62,9 \% \times 37,1 \%)$ foram semelhantes às de estudos encontrados na literatura (Hack et al., 2008; Oepkes et al., 2017).

Achado interessante do presente trabalho foi a ocorrência de doenças crônicas em maior proporção na população de fetos únicos, tais como Diabetes mellitus (7,9 \% x 1,4\%; RR= 5,72; IC95\% 2,42-13,48), HAC $(23,7 \% \times 6,4 \% ; R R=$ 3,68; IC 95\% 2,47-5,46) e obesidade (15,3\% x 5,3\%; RR = 2,90; IC95\% 1,84-4,57). Tais dados discordam do que encontramos em outros estudos. Quanto à 
prevalência de Diabetes, Schwartz e colaboradores (1999) encontraram 7,7 \% em gestações gemelares $\times 4,1 \%$ em gestações de fetos únicos, diferença esta que se mostrou estatisticamente significativa $(p<0,05)$. Luo e colaboradores (2006), em um estudo de coorte retrospectivo realizado nos EUA, com uma casuística de mais de 100.000 gestações gemelares e 5.000 .000 fetos únicos, mostraram que as prevalências de doença hipertensiva e obesidade foram maiores na população de gemelares. Achados semelhantes são vistos no estudo de Santana e colaboradores (2016). Esses autores, encontraram prevalências maiores em grupos de gestações gemelares. Levando-se em consideração essas características, a comparação dos grupos de pacientes nos faz pensar que a existência de uma maior prevalência destas intercorrências nas gestações únicas se deve ao fato de que nosso estudo foi desenvolvido em um serviço terciário de referência, com um perfil populacional diferenciado, com risco mais provável de ser eletiva a prematuridade nesse grupo.

Aprofundando a discussão sobre as intercorrências maternas, houve mais analgesia de parto, parto cesárea e complicações puerperais na população de gestantes gemelares, quando comparada aos fetos únicos, similarmente aos resultados encontrados na literatura (Campbell, 2003; Barrett, 2014; ACOG, 2014; Santana et al., 2016). Esses achados são compreensíveis, uma vez que a gestação gemelar apresenta maior potencial intrínseco de distocias, tanto em fase ativa quanto no período expulsivo, e morbidades secundárias a elas. As altas taxas de cesárea podem ser justificadas pelas maiores prevalências de apresentações anômalas, prolapso de cordão e descolamento de placenta no parto do segundo gemelar, além de trabalhos de parto e período expulsivo mais prolongados, especialmente por distocia funcional (Vogel et al., 2014; Barrett, 2014; Melamed et al., 2016). O período puerperal não é diferente: as maiores ocorrências de distocias (secundárias à hiperdistensão uterina e situações/apresentações fetais anômalas) e de partos operatórios, fazem com que haja maiores índices de complicações puerperais, notadamente aquelas relacionadas a infecções, hemorragias pós-parto e tromboses venosas (Trojner-Bregar et al., 2013; Stach et al., 2014; Dinis et al., 2015). 
$\mathrm{Na}$ análise dos desfechos neonatais, observou-se que tanto nas gestações únicas como nas gemelares, a prematuridade foi um relevante fator de risco para todos os resultados adversos, especialmente quando a IG foi inferior a 32 semanas (Hack et al., 2008; Corsello \& Piro, 2010; Ribicic et al., 2015). Outro fator de risco para Apgar de $1^{\circ}$ e $5^{\circ}$ minuto $<7$ foi o diagnóstico de SFA nas gestações únicas, fato este já bem conhecido e documentado por outros autores (Lai et al., 2017; Thavarajah et al., 2017). O possível déficit no aporte de oxigênio intraparto pode levar a alterações metabólicas que comprometem as variáveis biofísicas avaliadas no índice de Apgar, que são tão maiores quanto menores forem as idades gestacionais em que ocorrem, uma vez que os mecanismos de compensação do RN PT são de pior qualidade. Esse dado é reforçado pelo achado de que filhos de mães que não tiveram Diabetes ou doença hipertensiva, ou seja, doenças que levam a vasculopatia e lesão placentária tiveram risco menor desse resultado adverso. Talvez esse achado relacionado ao SFA não seja observado nas gestações gemelares porque a maioria das indicações de cesárea antecederam fases mais avançadas do trabalho de parto, nas quais o risco de SFA é maior. Nas gestações gemelares, a RCIU configurou como fator de risco para Apgar de $1^{\circ}$ minuto $<7$, o que poderia demandar resoluções anteriores ao trabalho de parto.

Avaliando a influência da via de parto sobre os índices de Apgar, observouse que o parto vaginal protegeu RN de gestações únicas do Apgar de $1^{\circ}$ minuto $<7$, mas aumentou o risco de ambos os índices de Apgar $<7$, de 1ํㅡ e $5^{\circ}$ minutos, em RN gemelares. Uma explicação que pode ser aventada para esse achado é a ocorrência de piores condições de nascimento do segundo gemelar. Já a corticoindução reduziu o risco de índices de Apgar $<7$, tanto no $1^{\circ}$ como no $5^{\circ}$ minuto nas gestações gemelares e apenas no $1^{\circ}$ minuto nas gestações únicas. Esse efeito protetor dos corticosteroides é corroborado por alguns autores como Chauhan e colaboradores (2010), Stach e colaboradores (2014) e Melamed e colaboradores (2016). Entretanto, um possível viés do nosso estudo é o fato de que, pelo risco elevado de prematuridade, a utilização de corticoide pré-natal pode ter ocorrido de maneira adequada e com a administração mais flexível de um ciclo de "resgate" $\left(2^{\circ}\right.$ 
ciclo) nas gestações gemelares, adicionando maior proteção aos RN destas, apesar de faltarem evidências que comprovem este fato na literatura.

$\mathrm{Na}$ análise da morbidade composta, o efeito da IG sobre esse resultado ficou evidente, especialmente em $\mathrm{RN}$ que nasceram antes da $28^{\mathrm{a}}$ e $32^{\mathrm{a}}$ semana, se considerarmos gestações únicas e gemelares, respectivamente. Além disso, a monocorionicidade tem uma influência significativa sobre esse resultado adverso entre os gemelares, uma vez que ser gêmeo DC figurou como fator de proteção (RR = 0,54; IC95\% 0,30-0,98; p=0,04) (Lee et al., 2006; Doss et al., 2012; Goya et al., 2015). A monocorionicidade apresenta algumas complicações intrínsecas como RCIU seletiva, STFF, sequência anemia-policitemia e monoamnionicidade que aumentam as taxas de morbimortalidade nesse grupo de gemelares (Rao et al., 2004; Harper et al., 2013; Cincotta et al., 2016). Comparativamente às gestações DC, essas intercorrências que ocorrem secundariamente a uma perfusão assimétrica dos gêmeos, por anastomoses das vasculaturas placentárias de ambos os fetos, são mais comuns nas gestações MC (Miller et al., 2012; Verbeek et al., 2016). Além disso, pode haver maior risco de inserção marginal ou velamentosa do cordão na monocorionicidade, resultando em discordâncias importantes nas divisões dos leitos placentários (Machin, 2004; Kent et al., 2012). A deficiência nutricional e de oxigenação se refletirão na ocorrência de maior morbidade composta entre esses gêmeos. Cumpre destacar que apesar de o parto vaginal ter aumentado o risco de índices de Apgar $<7$ em gemelares, essa variável não aumentou morbidade composta, ficando os baixos índices de Apgar como resultado provável de mecanismos hipóxicos. Vale reforçar que os dados devem ser avaliados com cautela, uma vez que há intervalos de confiança bastante amplos para algumas variáveis utilizadas na análise.

O óbito neonatal, assim como a morbidade composta, teve na prematuridade seu principal fator de risco, o que vai ao encontro das evidências encontradas (Hack et al, 2008; Lopriore, 2012). A prematuridade é responsável por altos índices de morbidade e mortalidade perinatais e a probabilidade de sobrevida neonatal aumenta com a IG de resolução (Baschat et al, 2007; Lees et al., 2013). Não haver hipertensão e obesidade materna figurou como fator de proteção para óbito no 
grupo de RN únicos, provavelmente pela ausência do comprometimento causado por essas doenças e por haver menor necessidade de resoluções eletivas na prematuridade motivadas por essas condições de risco. De importância foi o achado de SFA como variável que aumentou o risco de óbito neonatal no grupo de gemelares, reforçando o resultado anterior relacionado à morbidade composta. Cabe destacar que todas as condições que foram selecionadas para fazer parte da variável chamada morbidade composta, ou seja, EIV, LMPV, EHI, ECN, SDR e sepse estão associadas a elevados índices de mortalidade (Garite et al., 2004; Masheer et al., 2015; Hunter et al., 2017).

A hipoglicemia neonatal também foi um resultado adverso dependente da IG de nascimento, mais prevalente entre os RN PT moderados e tardios. Um achado da análise univariada que merece ser discutido é a hipoglicemia neonatal diagnosticada em gemelares com características de SFC. Sabe-se que, para aumentar a oferta de glicose, modificações metabólicas significativas ocorrem nesses fetos, representadas pela redução da glicogênese e aumentos da glicogenólise e neoglicogênese (Cornblath et al., 2000; Rozance, 2014; Fumagalli et al., 2016). Esses desvios do metabolismo certamente repercutirão em menores ofertas de glicose nas primeiras horas de vida do RN. Apesar de muito compreensível, esses achados não foram reproduzidos pela análise multivariada, talvez por uma casuística de fetos acometidos por sofrimento crônico não ter sido suficiente. Um dado que reforça a hipótese de veracidade da análise univariada é o efeito protetor que o parto vaginal teve sobre esse resultado adverso em ambas as populações, situação esta em que a amamentação sob livre demanda pode ser estabelecida mais precocemente. Problemas na amamentação também podem existir colaborando na permanência da gestação na adolescência como fator de risco para hipoglicemia em gemelares. Ausência de Diabetes mellitus materna conferiu aos RN únicos proteção para esse desfecho, fato esse já bem documentado por outros autores (Doss et al., 2012; Rashid et al., 2017; MendezFigueroa et al., 2017).

Quanto à icterícia, um dado interessante é que nas gestações gemelares, RN de mães sem companheiro têm probabilidade maior de apresentarem este 
desfecho. Além de ser surpreendente, esse resultado não pôde ser justificado por outros estudos. Mais uma vez, prematuridade foi fator de risco para icterícia em ambos os grupos de $\mathrm{RN}$ e isso pode claramente ser explicado pela imaturidade metabólica dos mesmos (Hartley et al., 2001; Moerschel et al., 2008; Bhutani et al. 2016). Diabetes foi um fator de risco para icterícia em fetos únicos e RCIU foi para gemelares. Já são bem conhecidos os motivos que levam a esses achados. Ambos estão relacionados aos estados hipóxicos existentes nas duas condições, resultando na produção fetal compensatória aumentada de glóbulos vermelhos, seguida de uma destruição aumentada na vida extrauterina (Gardner et al., 1995; Bennasar et al., 2017). Porém, hipóteses podem ser levantadas do porque ambos não configuram como fatores de risco para as duas populações. A RCIU pode ser um fator de risco na gemelaridade devido à existência da perfusão assimétrica dos fetos na monocorionicidade, que levaria não só a restrição do crescimento, mas também a transfusão feto-fetal e a sequência anemia-policitemia (Lucewicz et al., 2016; Slaghekke et al. 2016). Essa explicação é reforçada pelo achado da monocorionicidade como fator de risco para icterícia nesse grupo. $O$ fato da Diabetes não figurar como fator de risco na gemelaridade pode ser consequência da casuística do estudo.

O desfecho óbito fetal foi discutido neste estudo pela sua relevância, mas a análise das variáveis como fatores de risco ficou prejudicada por prevalências nulas de algumas delas. Um dado de importância foi a elevada prevalência de óbitos fetais em idades gestacionais inferiores a 28 semanas, tanto em gestações únicas como em gemelares, podendo estar esse fato relacionado a condições patológicas fetais mais graves que promovem a morte em IG precoces. Na gemelaridade, as complicações da monocorionicidade como doenças graves poderiam ser aventadas como causas, porém esse resultado não pode ser reproduzido pela análise multivariada. Mais uma vez, o número insuficiente de sujeitos pode ser a causa. Resultados semelhantes foram demonstrados em outros estudos (Hillman et al., 2011; Gao et al., 2012).

O presente trabalho tem características que the dão um caráter de importância. O número de gestantes incluídas, quando comparada a de outros 
estudos, foi expressivo. Além disso, o pareamento das pacientes do grupo de gemelares e fetos únicos foi rigoroso, havendo seleção de pacientes na mesma IG, que foram atendidas na mesma época e com resolução de suas gestações dentro de no máximo uma semana de distância entre elas. Além disso, houve poucas exclusões devido a preenchimento incompleto dos prontuários. Outro dado de importância foi o grande número de variáveis analisadas como fatores de risco e a quantidade significativa de gestantes nas quais a administração de corticóide anteparto não havia ocorrido, permitindo melhor avaliação dessa variável como fator de risco.

O estudo em questão tem algumas limitações como seu caráter retrospectivo que pode levar a coleta inadequada de informações e o fato de ser caso-controle que pode levar a vieses de seleção. Além disso, o número de fetos únicos obtido é menor que o de fetos gemelares. Apesar de expressiva, a casuística pode ter sido insuficiente para melhor análise de alguns desfechos. Ainda, o fato de analisarmos alguns resultados considerando a população de gemelares como um todo, apesar de diferentes corionicidades, pode ter interferido nos resultados.

Os resultados apresentados no presente estudo colaboram acrescentando conhecimento sobre a gemelaridade. Além de reforçar dados já existentes, traz novos achados que estimulam discussão sobre a assistência obstétrica fornecida nos dias atuais. Novos estudos deverão ser realizados com maiores casuísticas e diferenciando as gestações gemelares de acordo com a corionicidade das mesmas. 
8. CONCLUSÕES 
8.1. Prematuridade $<37$ semanas, SFA aumentam o risco de Apgar de $1^{\circ}$ minuto $<7$ nas gestações únicas, enquanto RCIU, prematuridade $<34$ semanas e parto vaginal o fazem na gestação gemelar. Ausência de Diabetes e hipertensão materna e parto vaginal protegem o $\mathrm{RN}$ deste resultado. A corticoindução protege $\mathrm{RN}$ gemelares deste desfecho.

8.2. SFA aumenta 0 risco de Apgar de $5^{\circ}$ minuto $<7$ nas gestações únicas. Prematuridade $<32$ semanas é fator de risco para este desfecho em ambas as populações de RN. RCIU, Diabetes materno e parto vaginal aumentam o risco de Apgar de 5 minuto $<7$ na gestação gemelar. A corticoindução protege RN únicos e gemelares deste desfecho.

8.3. Prematuridade $<28$ semanas é fator de risco para morbidade composta em fetos únicos. Nas gestações gemelares, SFA, prematuridade $<32$ semanas e monocorionicidade aumentam o risco deste desfecho.

8.4. Prematuridade $<34$ e $<32$ semanas são fatores de risco para óbito neonatal em fetos únicos e gemelares, respectivamente. SFA também é fator de risco para gemelares. Ausência de hipertensão e obesidade materna protegem os gemelares deste desfecho.

8.5. Prematuridade $<32$ semanas é fator de risco para hipoglicemia neonatal em fetos únicos. Parto vaginal e ausência de Diabetes materno protegem o RN único deste desfecho. Prematuridade $<34$ semanas e ter oligohidrâmnio aumentam o risco de hipoglicemia no RN gemelar. O parto vaginal o protege deste desfecho.

8.6. Hipertensão e Diabetes materna e prematuridade $<32$ semanas são fatores de risco para icterícia nos $\mathrm{RN}$ únicos. Mães sem companheiro, prematuridade <37 semanas, corticoindução e monocorionicidade são fatores de risco para gemelares. Não ter RCIU protege o RN da gestação múltipla de ter icterícia.

8.7. A análise dos fatores de risco para óbito fetal ficou prejudicada pela casuística insuficiente. 


\section{REFERÊNCIAS BIBLIOGRÁFICAS}


1. American College of Obstetricians and Gynecologists. Multiple gestation: complicated twin, triplet and higher order multifetal pregnancy. ACOG practice bulletin no. 56. Washington, DC: The College; 2004 (reafirmado em 2009).

2. American College of Obstetricians and Gynecologists; Society for Maternal-Fetal Medicine. ACOG Practice Bulletin No. 144: Multifetal gestations: twin, triplet, and higher-order multifetal pregnancies. Obstet Gynecol 2014; 123(5):1118-32.

3. Ananth C, Demissie K, Smulian J, Vintzileos A. Placenta previa in singleton and twin births in the United States, 1989 through 1998: a comparison of risk factor profiles and associated conditions. American Journal of Obstetrics and Gynecology 2003; 188(1):275-81.

4. Ananth C, Smulian J, Demissie K, Vintzileos A, Knuppel R. Placental abruption among singleton and twin births in the United States: risk factor profiles. American Journal of Epidemiology 2001; 153(8):771-8.

5. Armson BA, O'Connell C, Persad V, Joseph KS, Young DC, Baskett TF. Determinants of perinatal mortality and serious neonatal morbidity in the second twin. Obstet Gynecol 2006; 108:556-64.

6. Barrett JF. Twin delivery: method, timing and conduct. Best Pract Res Clin Obstet Gynaecol 2014; 28(2):327-38.

7. Barrett JF, Hannah ME, Hutton EK, Willan AR, Allen AC, Armson BA, Gafni A, Joseph KS, Mason D, Ohlsson A, Ross S, Sanchez JJ, Asztalos EV; Twin Birth Study Collaborative Group. A randomized trial of planned cesarean or vaginal delivery for twin pregnancy. Twin Birth Study Collaborative Group. N Engl J Med 2013; 369:1295-305. 
8. Baschat AA, Cosmi E, Bilardo CM, Wolf H, Berg C, Rigano S, Germer U, Moyano D, Turan S, Hartung J, Bhide A, Müller T, Bower S, Nicolaides KH, Thilaganathan B, Gembruch U, Ferrazzi E, Hecher K, Galan HL, Harman CR. Predictors of neonatal outcome in early-onset placental dysfunction. Obstet Gynecol 2007; 109(2 Pt 1):253-61.

9. Bennasar M, Eixarch E, Martinez JM, Gratacós E. Selective intrauterine growth restriction in monochorionic diamniotic twin pregnancies. Semin Fetal Neonatal Med 2017; 19.pii: S1744-165X(17)30048-3.

10. Berghella V, Odibo A, To M, Rust O, Althuisius S. Cerclage for short cervix on ultrasound meta-analysis of trials using individual patient level data. Obstet Gynecol 2005; 106:181-9.

11. Bhide A, Thilaganathan B. What prenatal diagnosis should be offered in multiple pregnancy? Best Pract Res Clin Obstet Gynaecol 2004; 18(4): 531-542.

12. Bhutani VK, Wong RJ. Risk profiles for haemolytic and nonhaemolytic neonatal jaundice. Acta Paediatr 2016; 105(12):1387-1388.

13. Blickstein I, Reichman B, Lusky A, Shinwell ES: Plurality-dependent risk of severe intraventricular hemorrhage among very low birth weight infants and antepartum corticosteroid treatment. Am J Obstet Gynecol 2006; 194: 1329-1333.

14. Blickstein I, Shinwell ES, Lusky A, Reichman B: Plurality-dependent risk of respiratory distress syndrome among very-low-birthweight infants and antepartum corticosteroid treatment. Am J Obstet Gynecol 2005; 192: 360-364.

15. Boyle B, McConkey R, Garne E, Loane M, Addor MC, Bakker MK, Boyd PA, Gatt M, Greenlees R, Haeusler M, Klungsøyr K, Latos-Bielenska A, Lelong N, McDonnell R, Métneki J, Mullaney C, Nelen V, O'Mahony M, Pierini A, Rankin J, Rissmann A, 
Tucker D, Wellesley D, Dolk H. Trends in the prevalence, risk and pregnancy outcome of multiple births with congenital anomaly: a registry-based study in 14 European countries 1984-2007. BJOG 2013; 120:707-16.

16. Breathnach FM, Malone FD. Fetal Growth Disorders in Twin Gestations. Semin Perinatol 2012; 36:175-181.

17. Breathnach FM, McAuliffe FM, Geary M, Daly S, Higgins JR, Dornan J, Morrison JJ, Burke G, Higgins S, Dicker P, Manning F, Mahony R, Malone FD; Perinatal Ireland Research Consortium. Definition of intertwin birth weight discordance. Obstet Gynecol 2011; 118:94-103.

18. Campbell DM, Templeton A. Maternal complications of twin pregnancy. International Journal of Gynecology and Obstetrics 2004; 84:71-3.

19. Catov JM, Ness RB, Kip KE, Olsen J. Risk of early or severe preeclampsia related to pre-existing conditions. International Journal of Epidemiology 2007; 36:412-9.

20. Chauhan SP, Scardo JA, Hayes E, Abuhamad AZ, Berghella V. Twins: prevalence, problems, and preterm births. Am J Obstet Gynecol 2010; 203(4):30515.

21. Cheung YB, Yip P, Karlberg J. Mortality of twins and singletons by gestational age: a varying-coefficient approach. Am J Epidemiol 2000; 152:1107-16.

22. Cincotta R, Kumar S. Future directions in the management of twin-to-twin transfusion syndrome. Twin Res Hum Genet 2016; 19(3): 285-91.

23. Conde-Agudelo A, Belizan J, Lindmark G. Maternal morbidity and mortality associated with multiple gestations. Obstet Gynecol 2000; 95: 899-904. 
24. Cornblath M, Ichord R. Hypoglycemia in the neonate. Semin Perinatol 2000; 24(2):136-49.

25. Corsello G., Piro, E. The Word of twins: an update. The Journal of Maternal-Fetal and Neonatal Medicine 2010; 23(S3): 59-62.

26. Crowther CA, Han S. Hospitalisation and bed rest for multiple pregnancy. Cochrane Database Syst Rev 2010; 7;(7):CD000110.

27. D'Antonio F, Khalil A, Dias T, Thilaganathan B, Southwest Thames Obstetric Research Collaborative (STORK). Weight discordance and perinatal mortality in twins: analysis of the Southwest Thames Obstetric Research Collaborative (STORK) multiple pregnancy cohort. Ultrasound Obstet Gynecol 2013; 41:643-8.

28. Day MC, Barton JR, O'Brien JM, Istwan NB, Sibai BM. The effect of fetal number on the development of hypertensive conditions of pregnancy. Obstet Gynecol 2005; 106:927-31.

29. De Vries LS, Eken P, Dubowitz LMS. The spectrum of leukomalacia using cranial ultrasound. Behav Brain Res 1992; 49: 1-6.

30. Dias T, Akolekar R. Timing of birth in multiple pregnancy. Best Pract Res Clin Obstet Gynaecol 2014; 28(2):319-26.

31. Dinis SR, Domingues AP, Belo A, Couto D, Fonseca E, Moura P. Do induced twin pregnancies influence the obstetric and neonatal results of multiple births born before 32 weeks? Comparison to spontaneous gestation. Rev Bras Ginecol Obstet 2015; 37(5): 216-21. 
32. Dodd JM, Grivell RM, Crowther CA. Multiple pregnancy. In: James DK, Steer PJ, Weiner CP, Crowther CA, Gonik G editor(s). High Risk Pregnancy: Management Options. $4^{\text {th }}$ Edition. Edinburgh, UK: Elsevier Saunders, 2010.

33. Dodd JM, Jones L, Flenady V, Cincotta R, Crowther CA. Prenatal administration of progesterone for preventing preterm birth in women considered to be at risk of preterm birth. Cochrane Database Syst Rev 2013; 31; (7):CD004947.

34. Doss AE, Mancuso MS, Cliver SP, Jauk VC, Jenkins SM. Gestational age at delivery and perinatal outcomes of twin gestations. Am J Obstetr Gynecol 2012: 207:410 e411-410 e416.

35. Easter SR, Lieberman E, Carusi D. Fetal presentation and successful twin vaginal delivery. Am J Obstet Gynecol 2016;214(1):116.e1-116.e10.

36. Eriksson AW, Fellman J. Temporal trends in the rates of multiple maternities in England and Wales. Twin Res Hum Genet 2007; 10: 626-32.

37. Flenady V, Reinebrant HE, Liley HG, Tambimuttu EG, Papatsonis DN. Oxytocin receptor antagonists for inhibiting preterm labour. Cochrane Database Syst Rev 2014; 6;(6):CD004452.

38. Flenady V, Wojcieszek AM, Papatsonis DN, Stock OM, Murray L, Jardine LA, Carbonne B. Calcium channel blockers for inhibiting preterm labour and birth. Cochrane Database Syst Rev 2014; 5;(6):CD002255.

39. Fox NS, Saltzman DH, Klauser CK, Peress D, Gutierrez CV, Rebarber A. Prediction of spontaneous preterm birth in asymptomatic twin pregnancies with the use of combined fetal fibronectin and cervical length. Am J Obstet Gynecol 2009; 201: 313.e1-5. 
40. Fumagalli M, Schiavolin P, Bassi L, Groppo M, Uccella S, De Carli A, Passera S, Sirgiovanni I, Dessimone F, Consonni D, Acaia B, Ramenghi LA, Mosca F. The impact of twin birth on early neonatal outcomes. Am J Perinatol 2016; 33(1):63-70.

41. Galea P, Jain V, Fisk NM. Insights into the pathophysiology of twin-twin transfusion syndrome. Prenat Diagn 2005; 25: 777-785.

42. Gao Y, He Z, Luo Y, Sun H, Huang L, Li M, Zhou Y, Chen B, Fang Q. Selective and non-selective intrauterine growth restriction in twin pregnancies: high-risk factors and perinatal outcome. Arch Gynecol Obstet 2012; 285(4):973-8.

43. Gardner MO, Goldenberg RL, Cliver SP, Tucker JM, Nelson KG, Copper RL. The origin and outcome of preterm twin pregnancies. Obstet Gynecol 1995; 85(4):553-7.

44. Garite TJ, Clark RH, Elliott JP, Thorp JA. Twins and triplets: the effect of plurality and growth on neonatal outcome compared with singleton infants. Am J Obstet Gynecol 2004; 191(3):700-7.

45. Glinianaia SV, Rankin J, Wright C. Congenital anomalies in twins: a registerbased study. Hum Reprod 2008; 23:1306-11.

46. Goya M, Cespedes MC, Camba F, Capote S, Felipe A, Reixachs A, Medina D, Gorraiz V, Pin S, Halachian C, Gracia A, Perapoch J, Cabero L, Carreras E. Antenatal corticosteroids and perinatal outcomes in infants born at 23-25 weeks of gestation. J Matern Fetal Neonatal Med 2015; 28(17):2084-9.

47. Hack KE, Derks JB, de Visser VL, Elias SG, Visser GH. The natural course of monochorionic and dichorionic twin pregnancies: a historical cohort. Twin Res Hum Genet 2006; 9(3):450-5. 
48. Hack KEA, Derks JB, Elias SG, Franx A, Roos EJ, Voerman SK, Bode CL, Koopman-Esseboom C, Visser GH. Increased perinatal mortality and morbidity in monochorionic versus dichorionic twin pregnancies: clinical implications of a large dutch cohort study. BJOG 2008:115:58-67.

49. Harkness UF, Crombleholme TM. Twin-Twin Transfusion Syndrome: where do we go from here? Semin Perinatol 2005; 29:296-304.

50. Harper LM, Weis MA, Odibo AO, Roehl KA, Macones GA, Cahill AG. Significance of growth discordance in appropriately grown twins. Am J Obstet Gynecol 2013; 208: 393.e1-5.

51. Hartley RS, Emanuel I, Hitti J. Perinatal mortality and neonatal morbidity rates among twin pairs at different gestational ages: optimal delivery timing at 37 to 38 weeks' gestation. Am J Obstet Gynecol 2001; 184:451-8.

52. Hillman SC, Morris RK, Kilby MD. Co-twin prognosis after single fetal death: a systematic review and meta-analysis. Obstet Gynecol 2011; 118(4):928-40.

53. Horbar JD. The Vermont Oxford Network: evidence based quality improvement for neonatology. Pediatrics 1999; 103: 350-9.

54. Hunter T, Shah J, Synnes A, Shivananda S, Ryan G, Shah PS, Murphy KE. Neonatal outcomes of preterm twins according to mode of birth and presentation. $J$ Matern Fetal Neonatal Med 2017; 8:1-7.

55. Kent EM, Breathnach FM, Gillan JE, McAuliffe FM, Geary MP, Daly S, Higgins JR, Hunter A, Morrison JJ, Burke G, Higgins S, Carroll S, Dicker P, Manning F, Tully $\mathrm{E}$, Malone FD. Placental pathology, birthweight discordance, and growth restriction in twin pregnancy: results of the ESPRiT Study. Am J Obstet Gynecol 2012; 207(3): 220.e1-5. 
56. Kinzler WL, Ananth CV, Vintzileos AM. Medical and economic effects of twin gestations. J Soc Investig 2000; 7:321-7.

57. Lai S, Flatley C, Kumar S. Perinatal risk factors for low and moderate five-minute Apgar scores at term. Eur J Obstet Gynecol Reprod Biol 2017; 210:251-256.

58. Lee YM, Cleary-Goldman J, D'Alton ME. The impact of multiple gestations on late preterm (near-term) births. Clin Perinatol 2006; 33(4):777-92.

59. Lees C, Marlow N, Arabin B, Bilardo CM, Brezinka C, Derks JB, Duvekot J, Frusca T, Diemert A, Ferrazzi E, Ganzevoort W, Hecher K, Martinelli P, Ostermayer E, Papageorghiou AT, Schlembach D, Schneider KT, Thilaganathan B, Todros T, van Wassenaer-Leemhuis A, Valcamonico A, Visser GH, Wolf H; TRUFFLE Group. Perinatal morbidity and mortality in early-onset fetal growth restriction: cohort outcomes of the trial of randomized umbilical and fetal flow in Europe (TRUFFLE). Ultrasound Obstet Gynecol 2013; 42(4):400-8.

60. Lie RT. Invited commentary: intersecting perinatal mortality curves by gestational age - are appearances deceiving? Am J Epidemiol 2000; 152:1117-9.

61. Lopriore E, Sluimers C, Pasman SA, Middeldorp JM, Oepkes D, Walther FJ. Neonatal morbidity in growth-discordant monochorionic twins: comparison between the larger and the smaller twin. Twin Res Hum Genet 2012; 15(4):541-6.

62. Lucewicz A, Fisher K, Henry A, Welsh AW. Review of the correlation between blood flow velocity and polycythemia in the fetus, neonate and adult: appropriate diagnostic levels need to be determined for twin anemia-polycythemia sequence. Ultrassound Obstet Gynecol 2016;47(2):152-7. 
63. Luo ZC, Simonet F, An N, Bao FY, Audibert F, Fraser WD. Effect on neonatal outcomes in gestacional hypertension in twin compared with singleton pregnancies. Obstet Gynecol 2006; 108(5): 1138-44.

64. Lynch A, McDuffie R Jr, Murphy J, Faber K, Orleans M. Preeclampsia in multiple gestation: the role of assisted reproductive technologies. Obstet Gynecol 2002; 99: 445-51.

65. Machin GA. Why is important to dignose chorionicity and how do we do it? Best Practice \& Research Clinical Obstetrics and Gynaecology. 2004; 18: 515-530.

66. Mackie FL, Morris RK, Kilby MD. Fetal brain injury in survivors of twin pregnancies complicated by demise of one twin: a review. Twin Res Hum Genet 2016; 19(3):262-7.

67. Magann EF, Sanderson M, Martin JN, Chauhan S. The amniotic fluid index, single deepest pocket, and two-diameter pocket in normal human pregnancy. Am J Obstet Gynecol 2000; 182(6):1581-8.

68. Martin JA, Hamilton BE, Osterman MJ. Three decades of twin births in the United States, 1980-2009. NCHS Data Brief 2012; 80:1-8.

69. Martin JA, Hamilton BE, Ventura SJ, Osterman MJ, Kirmeyer S, Mathews TJ, et al. Births: final data for 2009. Natl Vital Rep 2011;60:1-70.

70. Masheer S, Maheen H, Munim S. Perinatal outcome of twin pregnancies according to chorionicity: an observational study from tertiary care hospital. J Matern Fetal Neonatal Med 2015; 28(1): 23-25. 
71. Melamed N, Shah J, Yoon EW, Pelausa E, Lee SK, Shah PS, Murphy KE. The role of antenatal corticosteroids in twin pregnancies complicated by preterm birth. Am J Obstet Gynecol 2016; 215(4):482.e1-9.

72. Mendes-Figueroa H, Schuster M, Maggio L, Pedroza C, Chauhan SP, Paglia MJ. Gestational diabetes mellitus and frequency of blood glucose monitoring: a randomized controlled trial. Obstet Gynecol 2017 Jun 6.

73. Miller J, Chauhan SP, Abuhamad AZ. Discordant twins: diagnosis, evaluation and management. American Journal of Obstetrics and Gynecology 2012; 206(1):1020.

74. Moerschel SK, Cianciaruso LB, Tracy LR. A practical approach to neonatal jaundice. Am Fam Physician 2008; 1:77(9):1255-62.

75. Nassar AH, Usta IM, Khalil AM, Aswad NA, Seoud MA. Neonatal outcome of growth discordant twin gestations. Journal of Perinatal Medicine 2003; 31(4): 330336.

76. National Institute for Health and Clinical Excellence. Clinical guideline no. 129. Multiple pregnancy: management of twin and triplet pregnancies in the antenatal period. Royal College of Obstetricians and Gynaecologists, 2011.

77. Neilson JP, West HM, Dowswell T. Betamimetics for inhibiting preterm labour. Cochrane Database Syst Rev 2014; 5;(2):CD004352.

78. Ness A, Visintine J, Ricci E, Berghella V. Does knowledge of cervical length and fetal fibronectin affect management of women with threatened preterm labor? A randomized trial. Am J Obstet Gynecol 2007; 197: 426.e1-7. 
79. Oepkes D, Sueters M. Antenatal fetal surveillance in multiple pregnancies. Best Practice \& Research Clinical Obstetrics and Gynaecology. 2017; 38: 59-70.

80. Quintero RA, Kontopoulos E, Chmait RH. Laser Treatment of Twin-to-Twin Transfusion Syndrome. Twin Res Hum Genet 2016; 19(3):197-206.

81. Quintero RA, Morales WJ, Allen MH, Bornick PW, Johnson PK, Kruger M. Staging of twin-twin transfusion syndrome. Journal of Perinatology 1999; 19(8 Pt 1): 550-555.

82. Ong SS, Zamora J, Khan KS, Kilby MD. Prognosis for the co-twin following single-twin death: a systematic review. BJOG 2006; 113:992-8.

83. Pharoah PO: Risk of cerebral palsy in multiple pregnancies. Clin Perinatol 2006; 33: 301-313.

84. Ramsey PS, Repke JT. Intrapartum Management of Multifetal Pregnancies. Semin Perinatol 2003; 27(1):54-72.

85. Rao A, Sairam S, Shehata H. Obstetric complications of twin pregnancies. Best Practice \& Research Clinical Obstetrics and Gynaecology 2004; 18 (4): 557-76.

86. Rashid FB, Khatoon H, Hasnat MA, Amin R, Azad AK. Perinatal complications in diabetes mellitus with pregnancy: comparison between gestational diabetes mellitus (GDM) prior to pregnancy. Mymensingh Med J 2017; 26(1):124-130.

87. Ribicic R, Kranjcec I, Borosak J, Tumbri J, Mihovilovic Prajz L, Ribicic T. Perinatal outcome of singleton versus twin late preterm infants: do twins mature faster than singletons? J Matern Fetal Neonatal Med 2016; 29(9):1520-4. 
88. Rossi AC, Prefumo F. Impact of cord entanglement on perinatal outcome of monoamniotic twins: a systematic review of the literature. Ultrasound Obstet Gynecol. 2013; 41(2):131-5.

89. Rozance PJ. Update on neonatal hypoglycemia. Curr Opin Endocrinol Diabetes Obes $2014 ; 21(1): 45-50$.

90. Russell, Z., Quintero, R. A., \& Kontopoulos, E. V. Intrauterine growth restriction in monochorionic twins. Seminars in Fetal and Neonatal Medicine 2007, 12, 439449.

91. Sairam S, Costeloe K, Thilaganathan B. Prospective risk of stillbirth in multiplegestation pregnancies: a population-based analysis. Obstet Gynecol 2002; 100:63841.

92. Salihu HM, Bekan B, Alivu MH, Rouse DJ, Kirby RS, Alexander GR. Perinatal mortality associated with abruptio placenta in singletons and multiples. American Journal of Obstetrics and Gynecology 2005; 193(1):198-203.

93. Santana DS, Cecatti JG, Surita FG, Silveira C, Costa ML, Souza JP, Mazhar SB, Jayaratne K, Qureshi Z, Sousa MH, Vogel JP; WHO Multicountry Survey on Maternal and Newborn Health Research Network. Twin Pregnancy and Severe Maternal Outcomes: The World Health Organization Multicountry Survey on Maternal and Newborn Health. Obstet Gynecol 2016; 127(4):631-41.

94. Schwartz D, Daoud Y, Zazula P, Govert G, Bronsteen R, Wright D, Copes J. Gestational diabetes mellitus: metabolic and blood glucose parameters in singleton versus twin pregnancies. American Journal of Obstetrics and Gynecology 1999; 181(4):912-4. 
95. Sebire NJ, D'Ercole C, Soares W, Nayar R, Nicolaides KH. Intertwin disparity in fetal size in monochorionic and dichorionic pregnancies. Obstetrics and Gynaecology 1998; 91: 82-85.

96. Sebire NJ, Snijders RJ, Hughes K, Sepulveda W, Nicolaides KH. The hidden mortality of monochorionic twin pregnancies. Br J Obstet Gynaecol 1997; 104(10): 1203-7.

97. Shinwell ES. Neonatal morbidity of very low birth weight infants from multiple pregnancies. Obstet Gynecol Clin North Am 2005; 32(1):29-3.

98. Sibai BM, Hauth J, Caritis S, Lindheimer MD, MacPherson C, Klebanoff M, VanDorsten JP, Landon M, Miodovnik M, Paul R, Meis P, Thurnau G, Dombrowski $\mathrm{M}$, Roberts $\mathrm{J}$, McNellis D.Hypertensive disorders in twin versus singleton gestations. National Institute of Child Health and Human Development Network of MaternalFetal Medicine Units. Am J Obstet Gynecol 2000; 182:938-42.

99. Simpson LL. What you need to know when managing twins: 10 key facts. Obstet Gynecol Clin North Am 2015; 42(2): 225-39.

100. Slaghekke F, Zhao DP, Middeldorp JM, Klumper FJ, Haak MC, Oepkes D, Lopriore E. Antenatal management of twin-twin transfusion syndrome and twin anemia-polycythemia sequence. Expert Rev Hematol 2016; 9(8):815-20.

101. Smith GC, Fleming KM, White $\mathbb{R}$. Birth order of twins and risk of perinatal death related to delivery in England, Northern Ireland, and Wales, 1994-2003: retrospective cohort study. BMJ 2007;334:576-8.

102. Smith GC, Shah I, White IR, Pell JP, Dobbie R. Mode of delivery and the risk of delivery-related perinatal death among twins at term: a retrospective cohort study of 8073 births. BJOG 2005; 112:1139-44. 
103. Society for Maternal-Fetal Medicine, Simpson LL. Twin-twin transfusion syndrome. Am J Obstet Gynecol 2013; 208:3-18.

104. Soucie JE, Yang Q, Wen SW, Fung K, Walker M. Neonatal mortality and morbidity rates in term twins with advancing gestacional age. AM J Obstet Gynecol 2006; 195(1): 172-7.

105. Sperling L, Kiil C, Larsen LU, Brocks V, Wojdemann KR, Qvist I, Schwartz M, Jørgensen C, Espersen G, Skajaa K, Bang J, Tabor A. Detection of chromosomal abnormalities, congenital abnormalities, and transfusion syndrome in twins. Ultrasound Obstet Gynecol 2007; 29:217-226.

106. Stach SL, Liao AW, Brizot ML, Francisco RPV, Zugaib M. Maternal postpartum complications according to delivery mode in twin pregnancies. Clinics $2014 ; 69(7)$ : 447-451.

107. Thavarajah H, Flatley $\mathrm{C}$, Kumar $\mathrm{S}$. The relationship between the five-minute Apgar score, mode of birth and neonatal outcomes. J Matern Fetal Neonatal Med $2017 ; 26: 1-7$.

108. The ESHRE Capri Workshop Group: Multiple gestation pregnancy. Hum Reprod 2000; 15: 1856-1864.

109. Trojner-Bregar A, Tul N, Verdenik I, Novak Z, Blickstein I. Puerperal morbidity following repeat cesarean delivery in twin pregnancies. Arch Gynecol Obstet 2013; 288(3):551-4.

110. Verbeek L, Zhao DP, Te Pas AB, Middeldorp JM, Hooper SB, Oepkes D, Lopriore E. Hemoglobin differences in uncomplicated monochorionic twins in relation to birth order and mode of delivery. Twin Res Hum Genet 2016; 19(3): 241-5. 
111. Vogel JP, Holloway E, Cuesta C, Carroli G, Souza JP, Barrett J. Outcomes of non-vertex second twins, following vertex vaginal delivery of first twin: a secondary analysis of the WHO Global Survey on maternal and perinatal health. BMC Pregnancy Childbirth 2014; 31; 14:55.

112. Vogel JP, Torloni MR, Seuc A, Betrán AP, Widmer M, Souza JP, Merialdi M. Maternal and perinatal outcomes of twin pregnancy in 23 low- and middle-income countries. PLoS One 2013; 8:e70549.

113. Yamasmit W, Chaithongwongwatthana S, Tolosa JE, Limpongsanurak S, Pereira L, Lumbiganon P. Prophylactic oral betamimetics for reducing preterm birth in women with a twin pregnancy. Cochrane Database Syst Rev 2015; 8;(12):CD004733. 


\section{ANEXOS}




\section{ANEXO 1}

HOSPITAL DAS CLINICAS DA FACULDADE DE MEDICINA DE RIBEIRÃO PRETO DA UNIVERSIDADE DE SÄO PAULO

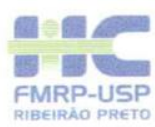

Ribeirão Preto, 24 de junho de 2014

Oficio $\mathrm{n}^{\circ} 2159 / 2014$

$\mathrm{CEP} / \mathrm{MGV}$

PROCESSO HCRP n ${ }^{\circ} 6431 / 2014$

Prezado Senhor,

O trabalho intitulado "AVALIAÇÃO DOS FATORES EPIDEMIOLÓGICOS, DIAGNÓSTICOS E TERAPÊUTICOS ASSOCIADOS À GEMELARIDADE E O IMPACTO DOS MESMOS SOBRE OS RESULTADOS MATERNOS E PERINATAIS", foi analisado "AD REFERENDUM" pelo Comitê de

Ética em Pesquisa e enquadrado na categoria: APROVADO, bem como a solicitacão de dispensa do Termo de Consentimento Livre e Esclarecido.

Este Comitê segue integralmente a Conferência Internacional de Harmonizaçâo de Boas Práticas Clínicas (IGH-GCP), bem como a Resoluçâo $n^{o}$ 196/96 CNS/MS.

Lembramos que devem ser apresentados a este CEP, o Relatório Parcial e o Relatório Final da pesquisa.

Atenciosamente.

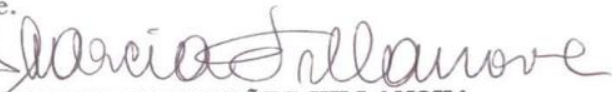

DR MARCIA GUIMARÃES VILLANOVA

Coordenadora do Comitê de Ética em

Pesquisa do HCRP e da FMRP-USP

Ilustrissimo Senhor

RODRIGO SOLER COLTRO

Depto. de Ginecologia e Obstetricia

Comitê de Ética em Pesquisa do HCRP e FMRP-USP FWA-00002733; IRB-00002186 e Registro PB/CONEP n 5440 14048-900 Ribeirão Preto SP (016) $3602-2228$
cep@hcrp.usp.br 